\title{
Intersonic shear rupture mechanism
}

\author{
Tarasov, B. G.
}

University of Western Australia, Australia

\begin{abstract}
According to the theory the rupture speed in solids for mode-I cracks is limited by the Rayleigh speed $c_{R}$ while mode-II cracks can propagate intersonically. These theoretical predictions and sustaining experiments were made for idealized conditions: for a crack propagating along a predetermined weak and straight-line crack path in homogeneous linear elastic materials. In real materials, however, the mode-I crack speed has never been observed to exceed $0.65 c_{R}$. The reason for that is the natural tendency for physical cracks to follow a wavy path and for microbranching, which results in a significant increase in microcrack population and, consequently, in the fracture energy. At the same time intersonic shear ruptures (mode-II cracks) have been reported for crustal earthquakes. It seems paradoxical because earthquake ruptures are normally associated with high complexity and extreme damage in the rupture zone.

The present paper shows that nature has provided special shear rupture mechanisms acting in hard rocks at high confining pressure which minimize the rupture energy causing the increase in rupture speed. These mechanisms are different for primary ruptures (continuous thin ruptures with uniform structure) and general faults (complex discontinuous systems). The general faults propagate in a jump-like manner forming a cascade of segments due to an advanced triggering mechanism. The advanced triggering mechanism triples the propagation speed of a general fault compared with primary fractures involved in the fault. The propagation of primary ruptures is facilitated by another mechanism, which is a fan-shaped self-equilibrated mechanism created on the basis of an echelon of rotating blocks representing the intrinsic nature of the shear crack structure. These two mechanisms acting in combination can provide intersonic propagation of general faults.
\end{abstract}

Keywords: shear rupture mechanism, intersonic propagation speed, earthquake, rockburst.

\section{Introduction}

Shear is the only form of rock mass rupture at depth that leads to large scale deformations accompanied by large energy release. Spontaneous development of new ruptures and reactivation of old ones cause earthquakes and rockbursts [1,2]. Modern seismology considers earthquakes mostly as a result of reactivation of existing geological faults and 
describes this process in terms of frictional laws [1,3,4]. This approach to the fault process bypasses a key question that is still unclear, regarding what mechanism can provide shear rupture development in pristine hard rocks at great depth. The importance of this question is based on the fact that all existing faults in the earth crust were initially formed in pristine rocks. Undoubtedly the development of new faults in pristine rocks within the crust takes place nowadays. The mechanics of shear rupture development at great depth and attainability of high speed (intersonic) are pressing questions relevant to seismic hazard. The present paper discusses some features of shear rupture development in pristine hard rocks at conditions of great depth (high confining pressure) which influence the maximum attainable speed.

To better understand the situation regarding shear rupture (mode-II crack) propagation, let us consider briefly a similar question for mode-I cracks. The theoretical limit for the mode-I crack speed $v$ in a homogeneous solid is the Rayleigh speed $c_{R}$ which is approximately $90 \%$ of the shear wave speed $c_{S}$ in the same material $[5,6]$. This limit is obtained by assuming that an opening crack will propagate along a perfectly straight crack path in the homogeneous material. In special experiments where such conditions were artificially provided the predicted limiting speed was approached, in particular, in tests conducted on fabricated weak planes in a homogeneous material by bonding two identical plates of a brittle polymer [7]. In real materials, however, the speed has never been observed to exceed $0.65 c_{R}$. Furthermore, in the overwhelming majority of cases the speed was only about $30-40 \%$ of $c_{R}$. The reason for that is the natural tendency for physical cracks to follow a wavy path and for microbranching, which results in a significant increase in microcrack population and, consequently, in the fracture energy [8-10].

For mode-II cracks the theory predicts the ability to propagate intersonically, that is at speeds between the compression wave speed $c_{P}$ and the shear wave speed $c_{S}[5,6,11$ 15]. The theoretical models consider again an idealized situation: a structureless crack propagating along a predetermined weak and straight-line crack path between two isotropic linear elastic solids. Experimental studies show that shear cracks in coherent, adhesive, straight-line interfaces can indeed propagate intersonically in various bonded bimaterials subjected to impact loading $[16,17]$. It should be noted that we have 
mentioned here experimental results obtained on cohesive ruptures only. Analogues experiments obtained on frictional models are less relevant to the subject of the present paper, which is the shear rupture development in pristine rocks.

The question is whether the available results, obtained for idealized conditions and homogeneous solids, can be used to verify the attainability of intersonic rupture speed in natural rocks at conditions of great depth typical for earthquakes and shear rupture rockbursts. By analogy with mode-I cracks one can suppose that the intersonic rupture speed is unattainable in real conditions, due to similar physical reasons: i) the natural tendency to follow a wavy crack path, ii) the development of very intensive crack population representing the fault structure, iii) the tendency to form segments linked by extremely damaged rock zones. However, considerable evidences of intersonic rupture speeds have been reported for crustal earthquakes [18-21]. It seems paradoxical because earthquake ruptures are normally associated with high complexity and extreme damage in the rupture zone.

This paper shows that hard rocks at high confining pressure acquire specific properties which distinguish them markedly from common rock behaviour - they become extremely brittle and lose shear resistance within a certain range of the shear rupture displacement [22]. The combination of these properties increases instability with depth and makes rupture abnormally violent. These hard rock features are caused by the intrinsic nature of the fault structure which is an echelon of blocks operating as hinges, essentially eliminating friction at high confining pressure. The frictionless concept allows the process of shear fracture development to be viewed from a new point of view.

It is shown here that nature has provided special mechanisms minimizing expenditure of energy at shear rupture development which should lead to increase in rupture speed. These mechanisms are different for primary ruptures (continuous thin ruptures with uniform structure) and general faults (complex discontinuous systems). Acting in combination these mechanisms can provide intersonic propagation of general faults. 


\section{Modern understanding of shear rupture mechanism}

A brief analysis of the modern understanding of shear rupture nucleation and propagation in rocks at triaxial compression is presented below. This subject has been explored extensively during the last few decades. The initial idea that shear ruptures grow from incipient flaws was refuted by stress analysis and experimental studies which revealed that a flaw can not propagate in its own plane [23]. The next concept was based on observations of intense micro-cracking prior to faulting. It was suggested that the shear rupture forms due to coalescence of distributed micro-cracks when their concentration reaches some critical level [24-28].

An important breakthrough in understanding of shear rupture development in hard rocks was made quite recently when acoustic emission technology and stiff servocontrolled loading systems became available [29-31]. It was established that a fault nucleates by local interaction between a few micro-cracks and propagates into the unfaulted regions by inducing new micro-crack growth at its tip. Figure 1a shows the basic concept of a model by Reches and Lockner [31] illustrating the geometry of interacting mode I cracks, which form a shear fracture extending along a dotted line. The tensile crack orientation is along the major compressive stress. The model proposes that in the highly stressed material, the dilation of one crack can induce dilation of closely spaced neighbouring cracks that were themselves on the verge of opening. The new crack should develop in the region of maximum tension, which is located at an angle of at least $30^{\circ}$ to the existing crack [26,32,33].

Figure 1

An echelon of blocks (slabs, beams) separated by such tensile cracks represents a specific fault structure which is typical for shear ruptures of all scales [1,2,25]. Photographs of the fault structure are shown later in Figure $2 \mathrm{~b}$ and Figure 10. The fault displacement along a similar block structure is accompanied by rotation, buckling and failure of the blocks. Existing models, e.g. [25,30,31,34-36], consider this process for all kind of rocks and all stress conditions as a fully frictional process. 
Three characteristic zones in the propagating shear ruptures were distinguished: i) a process zone that lies at the head of the rupture, where an echelon of micro-cracks develops; ii) a core zone consisting of comminuted rock material, which forms immediately behind the process zone; iii) a damage zone, which comprises a broader volume of more distributed irreversible deformation around the fault. An idealised shear rupture model comprising the process and core zones is shown in Figure 1b [31]. The core zone is indicated here as 'nucleus of fault zone'. The damage zone (not shown) well documented in laboratory and field observations is caused by tensile stresses acting outside of the shear rupture [37-40].

\section{Figure 2}

Figure 2 illustrates natural features of real faults: i) wavy crack path, ii) very significant rock damage and iii) segmentation. In accordance with modern understanding zones of linkage between an echelon of fault segments (jogs, overlaps, etc.) represent high strength barriers impeding static and dynamic fault propagation [1,37,41,42]. Summarising results of the conducted analysis we can conclude that the modern understanding of shear rupture mechanisms suggests (by analogy with mode-I cracks) that intersonic speed can unlikely be reached in real faults propagating in pristine rocks.

\section{Frictionless fault structure}

It was shown recently that hard rocks failed at high confining pressure (exceeding some critical level $\sigma_{3}>\sigma_{3}{ }^{c r}$ ) exhibit specific 'abnormal' post-peak properties that distinguish them markedly from common rock behaviour: they become extremely brittle with brittleness increasing with $\sigma_{3}$ and lose shear resistance within a certain range of shear rupture displacement [22]. Figure 3 illustrates the 'normal' and 'abnormal' rock behaviour obtained on dolerite specimens. The critical confining pressure for this rock is $\sigma_{3}{ }^{\mathrm{cr}} \approx 50 \mathrm{MPa}$. At $\sigma_{3}>{\sigma_{3}}^{\mathrm{cr}}$ rock brittleness increases with $\sigma_{3}$, the immediate post-failure resistance $\sigma_{\text {p.f }}$ becomes very low and normal frictional residual strength $\sigma_{\text {res }}$ is only mobilized after finite fault displacement. The combination of these features results in increasing instability with depth and makes rupture abnormally violent. Such unusual 
rock properties are caused by specific behaviour of the fault structure at these conditions. High confining pressure suppresses the formation of long tensile cracks, so that the fault structure comprises blocks that are short enough to withstand rotation without failure. This is possible in hard rocks only due to their very high strength. In this situation the blocks operate as hinges and friction between them essentially disappears.

Figure 3

Figure 4a shows schematically a fragment of such fault at four stages of its displacement. The fault resistance to shear in this case is a function of the block orientation to the fault axis (angle $\beta$ ). The interrelation between fault resistance $F^{\prime}$, normal reactive force $N^{\prime}$ and angle $\beta$ is shown in Figure 4b. Figure 4c demonstrates the variation of the normalized fault resistance $\left(F^{\prime} / N^{\prime}\right)$ versus angle $\beta$. The range of angle $\beta$ variation here is $\alpha \leq \beta \leq 180^{\circ}-\alpha$, where $\alpha=30^{\circ}$ is the angle of initial orientation of the tensile cracks in respect to the fault axis (as typically found for hard rocks). A dotted line on the graph represents the level of the normalized residual strength, corresponding to a coefficient of friction of 0.8 (typical for hard rocks).

\section{Figure 4}

The graph shows that the fault resistance decreases with displacement, continuing past the residual frictional resistance (at point $\mathrm{M}$ ) and reaches zero resistance at point $\mathrm{O}$, where $\beta=90^{\circ}$. At $\beta>90^{\circ}$ the fault resistance becomes negative which means that at this condition the block structure under the effect of the normal force $N$ creates an active force assisting the fault displacement. The greater is the angle $\beta$ the greater is the active force. Two parts of the graph $F^{\prime} / N^{\prime}$ versus $\beta$ lying above and below the horizontal axis indicate that the work done by the reactive $\left(F^{\prime}=F_{R}^{\prime}\right)$ and active $\left(F^{\prime}=F_{A}^{\prime}\right)$ forces within the total range of block rotation is equal to zero. When the blocks have completed their rotation at point $\mathrm{P}$ the friction within the fault structure is restored sharply and further displacement along the fault occurs in accordance with the friction law. 
The model shows that the block structure of shear fractures can create active forces under the effect of normal stress, which makes the fault resistance negative over a certain displacement. It should be emphasized that in practice the minimum post-failure resistance $\sigma_{\text {p.f }}$ (see Figure 3) of real faults stays greater then zero (but significantly lower than the residual strength $\sigma_{\text {res }}$ ). This is due to highly non-uniform activation of the frictionless mechanism along the fault, as will be discussed below.

The frictionless concept allows the process of shear fracture development to be viewed from a new point of view. A simple but well-founded classification of shear fractures is used in the paper, namely: i) primary fractures and ii) general faults. It will be shown that despite the similarity in their structures, each of which is represented by an echelon of rotating blocks, the development of these two forms of fractures is drastically different.

\section{Primary shear fracture}

\subsection{Structure}

Primary shear fractures are continuous thin ruptures with uniform structure and thickness ranging from fractions of a millimetre to a number of millimeters (see an example in Figure 2a). Figure 5 illustrates new principles of the primary fracture development. Figure 5a represents a potential fault before the onset of its development. The eventual fault structure, comprising an echelon of blocks, does not exist initially, but will be created (activated) sequentially during the fault development. The eventual (potential) structure is shown here to illustrate that the rotation of activated blocks within the fault zone causes a transient increase in the fault thickness (in the vertical direction) but does not affect the material body along the fault (in the horizontal direction). Orientations of major $\sigma_{1}$, minor $\sigma_{3}$, shear $\tau$ and normal $\sigma_{\mathrm{n}}$ stresses applied to the material body are shown in the picture.

Figure 5 
Five stages of the fault development are shown here. When shear stress approaches the level of ultimate shear strength the process of formation of the fault structure will start within the most suitable area of the material body determined by the local material strength and stress conditions. This process involves creation of tensile cracks and blocks between them and rotation of the blocks in response to the fault displacement. In accordance with the frictionless concept blocks representing the fault structure can rotate from the initial angle $\beta=\alpha$ up to the final angle $\beta=180^{\circ}-\alpha$, where $\alpha$ is the angle of initial orientation of the tensile cracks (and blocks) in respect to the fault axis. At the rotation a series of blocks eventually forms a fan-shaped structure at the head part of the propagating fracture (Figure 5f). The fan-shaped structure represents the process zone which is strictly determined in this model compared with the model by Reches and Lockner [31] discussed above and other existing models. The core zone in this case is represented by blocks that have completed their rotation. Within the core zone the friction is completely restored and the fault strength here is characterized by normal frictional resistance.

\subsection{Fan-shaped self-equilibrating mechanism}

The fan-shaped structure, the remarkable features of which are illustrated in Figure 6, is the key mechanism of dynamic fracture propagation. Figure 6a shows an opening fragment of the structure, with the fracture propagating from left to right and the shear direction indicated by dotted arrows. Rotating blocks of this fragment resist shearing due to the normal stress $\sigma_{n}$. This resistance (the reactive force $F_{R}^{\prime}$ ) can be very large at high confining pressure (or at great depth). The graph in Figure 4c shows that the normalized resistance to shear for a block structure oriented at angle $\alpha=30^{\circ}$ to the fault axis is initially double the residual strength. At smaller values of $\alpha$, which is possible for hard rocks, the resistance can be even greater.

Figure 6

A remarkable feature of the rotating blocks located in the second half of the fan structure (Figures $6 \mathrm{~b}$ and $6 \mathrm{c}$ ) is the creation of an active force $\mathrm{F}_{\mathrm{A}}^{\prime}$ under the effect of the 
same normal stress $\sigma_{\mathrm{n}}$. This force assists fracture propagation. At completion of the fanstructure formation (Figure 6c) the value of the active force becomes equal to the reactive force $\left(F_{A}^{\prime}=F_{R}^{\prime}\right)$. Thus the fan-shaped structure represents a self-equilibrating mechanism and can move as a wave, propagating the fracture under the action of relatively small shear stresses. Because the active force here is applied to the moving object (the fanshaped head) this situation can be compared symbolically with the principle of a rocket engine. It is known [5,43] that the limit of rupture speed can be significantly increased when the loading is applied directly at the propagating crack tip. The rupture head represented by the self-equilibrating fan-shaped structure can be treated as a physical model of the velocity weakening cohesive zone in elastodynamic shear crack models.

The nature of rock fracture development is that unstable propagation is foregone by a preceding phase of deformation. The correct understanding of the physical processes taking place at this phase is extremely important for predictive purposes. Knowing the physical mechanism it is possible, in particular, to determine with a higher degree of certainty the critical fracture length $\mathrm{L}_{\mathrm{cr}}$, which indicates the boundary between stable and unstable phases of the fracture process. Existing crack and friction-slider models do not consider the detailed physical mechanisms operating in the fracture zone and define the critical length independently of the fault structure [1,11,44]. For example, in crack models $L_{c r}$ is determined from the assumption that a characteristic fracture energy per unit area is required for the crack to propagate. In the stick-slip models, rupture is assumed to occur when the stress on the fault reaches the static friction value and the condition for dynamic instability exists.

The fan-shaped concept provides new information about the instability initiation. According to the model the instability starts when the fan-shaped mechanism creates an additional active force $F_{A}^{\prime}$ which disturbs the balance between the applied and reactive forces. For idealized conditions the minimum critical length $\mathrm{L}_{\mathrm{cr}}$ should correspond to the half length of the fan-shaped structure. The length $\mathrm{L}_{\mathrm{cr}}$ in this approach is a function of the geometrical characteristics of the fault structure (fault thickness, angle of the initial block orientation, distance between blocks, etc), and elastic parameters of the face material. This question will be considered in detail in a subsequent paper. 
A further important feature of the fan-shaped structure is the creation of compressive and tensile stresses within the opposite surfaces of the fracture (see Figure $6 d)$, which can initiate tensile cracks within the extension surface of the fracture. The existence of a damaged zone along the extension fracture surface is well documented and is explained by alternative mechanisms $[37,39,40]$. The fan-shaped structure represents an additional mechanism causing this known effect.

We can suppose that the fan-shaped structure can form not only during fracture propagation in pristine heterogeneous materials (rocks) but also at stick-slip displacement along pre-existing fracture surfaces. The gouge material normally created within such fractures during stick-slip experiments can possibly represent elements (blocks) of the fan-shaped structure. If so, the fan-shaped self-equilibrating mechanism can be considered as a universal mechanism of spontaneous shear rupture development in both cohesive and frictional types of ruptures.

\subsection{Forms of the rupture propagation}

It should be noted that in primary fractures the frictionless mechanism is activated within the fan-shaped head of the fracture only (in contrast with general faults discussed later). The core zone representing the majority of the fracture area exhibits normal residual frictional behavior. After completion of the fracture propagation the structure of primary fractures is regular, continuous and with normal frictional resistance.

The fan-shaped mechanism can provide two known forms (crack-like and pulselike) of fracture propagation. In the 'crack-like' models, fracture tip propagation is accompanied by displacement along the core zone [45-47]. The shear resistance in the core zone of the fan-shaped model corresponds to fully restored residual friction, so that a corresponding shear stress must be applied to cause displacement along this zone. If this stress is not sufficient, the fan-shaped head will travel in the manner of 'pulse-like' models [48-50]. In that case the core zone behind the dynamically moving head stays stable and the total displacement along the fault is very small. The total displacement $d$ is then associated with block rotation within the head only, given by $d=2 h \tan \alpha$, where $h$ is the fault thickness and $\alpha$ is the initial angle of the block orientation (see Figure 4a). Hence, pulse-like fracture creation due to independent moving of the fan-shaped head 
(independent on the core zone), and resulting very small displacement of the shear fracture, can create very curvilinear traces similar to that shown in Figure 2a. The waviness of the fracture in this case is determined by non-uniformity in material strength and local stress conditions.

\subsection{Two-dimensional fracture development}

Shear fracture is a very complicated structural system that propagates two-dimensionally from a hypocentre forming a fracture plane. Existing models that aim to describe twodimensional shear fracture propagation consider fractures of an extremely simplified version, without any internal structure. Our understanding of the important question of what kind of natural mechanisms provide two-dimensional shear fracture propagation is presented below.

\section{Figure 7}

Figure 7 shows a photograph [2] of a lineated hackly surface of a shear fracture initiated in quartzite at a deep mine (depth about $2000 \mathrm{~m}$ ). Ortlepp [2] points out that the lineated texture is not a result of shear traction as can often be observed on shear surfaces subjected to significant mutual displacement. The hackly surface contains footprints of rotating blocks that filled the shear rupture and have been washed away before the photograph was taken. These blocks are rock chips that look like fish scales. The footprints show that the blocks were arranged in an echelon of rows, and the photograph shows that the rows form curved lines. A white line in the picture reflects the orientation of rows in different areas of the plane.

\section{Figure 8}

Taking into account the observed structural features and the fan-shaped nature of the shear fracture propagation, the following two-dimensional model can be reconstructed. Figure 8 shows three stages of the fracture propagation. After the loss of stability at the hypocentre, the fracture, driven by the fan-shaped mechanism, propagates 
within a plane in all directions. Such propagation is possible due to segmentation of blocks (formation of scales). Dotted ellipses in the picture represent an echelon of rows comprising rock 'scales'. Within the elliptical front of the propagating fracture (shaded area) scales form the fan-shaped structure of the process zone, which propagates as a wave. Cross-sections of this fracture made in any direction should have a structure similar to that shown in Figure 5f. The distance (or speed) of propagation in different directions is proportional to shear stresses $\tau_{\varphi}$ acting in these directions, as illustrated in Figure 8. Due to the variation of $\tau_{\varphi}$ in different directions, the fracture acquires an ellipsoidal shape. Within a segment abc the mechanism of fracture formation must be different because in this segment the value of $\tau_{\varphi}$ is too small to provide adequate shear fracture development. We can suppose that in this area fracture development occurs in response to stress redistribution caused by propagation of other parts of the fracture.

It should be noted that geological evidence suggests very thin faults (about $1 \mathrm{~mm}$ ) for some earthquakes [51]. The possible mechanisms responsible for such fault formation were discussed above. We can suppose also that very thin faults can represent super-deep earthquakes (the deepest recorded earthquake occurred at a depth of $635 \mathrm{~km}$ [51]). According to the frictionless concept the increase in confining pressure makes faults thinner (due to the decrease in length of tensile cracks and, consequently, rotating blocks) and their behavior more brittle. The greater brittleness with increase in $\sigma_{3}$ (or depth) is explained as follows. The shorter are the blocks, the smaller is the fault displacement required to decrease the fault resistance to a given value.

In conclusion we can say that the fan-shaped mechanism activated in hard rocks at high confining pressure facilitates the shear rupture propagation which should cause the increase of rupture speed. However, the attainability of intersonic speed by primary fractures in pristine rocks has never been reported. At the same time there are considerable evidences about intersonically propagating shallow earthquakes [18-21], which are represented by complex general faults. This fact looks paradoxical because general faults associate with drastically greater rock damage compared with primary fractures. A possible mechanism responsible for this paradox is discussed below. 


\section{General fault}

\subsection{Segmentation (modern understanding)}

General faults are complex discontinuous systems comprising primary fractures, segments, junctions, overlap regions, and other geometrical complexities (see Figures 2b and 2c). Segmentation in the form of discontinuities and branching is a fundamental feature of general faults. Despite very intensive study of the nature of segmentation [1,40,42,52-56] no consensus of opinion has been reached regarding the physical mechanisms responsible for this phenomenon. Examples of different mechanisms that have been proposed include:

i) Segmentation as result of the linkage of pre-existing segments.

ii) Segments as an echelon of mode-I cracks involved in the structure of a general fault by analogy with tensile cracks in mode-II (or mode III) primary fractures.

iii) Segmentation as a result of separation of a continuous fault when it encounters stronger rock or the earth surface.

iv) Initiation of rupture on a branching fault due to stresses around a dynamically propagating rupture tip located off the main fault plane.

The interaction and linkage between an echelon of fault segments have also been studied extensively $[1,37,57,58]$. Linkage zones are normally represented by significantly fractured rocks. The role of the linkage zones in the faulting process was analyzed. It was established, in particular, that all types of jogs represent high strength barriers impeding static and dynamic fault propagation and motion [1,37,41,42].

\subsection{Segmentation (new approach)}

\subsubsection{Segmentation as a result of advanced fracture triggering}

The self-equilibrated fan-shaped mechanism acting in primary fractures facilitates fracture propagation due to neutralization of shear resistance in the fracture tip. The core zone, however, with fully mobilized residual friction and a wavy crack path provides significant resistance to displacement along the fracture. In large faults where large displacements must be accommodated, nature has provided a special mechanism that 
facilitates this process, decreasing friction along the fault and neutralizing the resistance caused by the wavy path. Segmentation is a key element of this mechanism.

\section{Figure 9}

In accordance with generally accepted concepts the formation of branches and linkage zones occurs in the following sequences illustrated schematically in Figure 9a. The general fault comprising two segments (1 and 2) propagates from left to right. Bold arrows here represent developing fractures while the dotted lines correspond to potential fractures. In accordance with existing concepts the fracture process in segment-2 can be initiated only after the fracture in segment- 1 has reached segment- 2 . When segment- 2 is initiated, segment-1 stops propagating further. The new stepped fracture (segment-2) in this case is merely the continuation of the previous one. According to this approach all steps between adjacent segments represent obstacles restricting fracture initiation in the next segment and the fault development as a whole.

Figure $9 \mathrm{~b}$ illustrates a new mechanism, which is advanced fracture triggering. The propagating fracture- 1 initiates a new fracture at point A due to the stress transfer at some distance ahead of the current fracture. The new fracture propagates bilaterally, both towards the current fracture and in the opposite direction. When the two approaching fractures meet they normally form a linkage zone. Possible linkage mechanisms will be discussed below. The following results of observations support the idea of advanced triggering:

i) Fault triggering is actively studied in seismology to understand initiation of new faults. Although the main focus of attention has been the analysis of situations where triggering of new ruptures occurs following some delay after the main event [1,59-62] there are evidences suggesting random heterogeneity in the faulting process where a number of sub-events are triggered practically simultaneously within the whole fault zone [63-65]. Evidences of earthquake complexities in forms of high variability of slip and stress drop in space [66-68] can also be treated as manifestations of the fracture triggering process. 
ii) Vermilye and Scholz [40] pointed out that results of structural analysis conducted by them for two neighboring segments could be interpreted as evidence of independent nucleation and linkage of initially isolated fault segments propagating towards each other. However, because this fact is in conflict with the common approach, they suggested an alternative mechanism for this fault segmentation.

iii) Results of analysis of the fault structure in zones linking segments also support the idea that the linked segments propagated in opposing directions. This question is discussed further below.

\subsubsection{Linkage of approaching segments}

Two photographs in Figure 10 show junctions of two overlapped segments. The diagrams between the photographs illustrate the sequence of such junction formation. In the diagrams, the propagating segments are shown by bold arrows while open arrows indicate the directions of shear. The left hand photograph clearly demonstrates that the two approaching segments are represented by primary fractures. Before meeting, the fractures deflected slightly due to interaction of their stress fields and have then propagated further forming an overlapping zone. When the overlap reaches some critical length the overlapping zone has separated into rotating blocks by the creation of tensile cracks resulting from shear along the overlapping zone. The right hand photograph shows more intensive echelon of blocks which evidences about greater violence and displacement associated with the joining process.

Figure 10

Hence, linkage zones between segments represent special joining shear fractures comprising an echelon of rotating blocks, as is typical for all types of shear fractures. Unlike primary shear fractures, which propagate due to the fan-shaped mechanism, the joining fractures are formed simultaneously due to shear within the overlap zone. In contrast with primary fractures, the joining fractures are relatively short and thick. Their function is to facilitate displacement of the general fault. The joining fractures create 
outward forces perpendicular to the fault axis, due to rotation of the blocks, thus unloading adjacent parts of the segments and decreasing friction in them. Open cracks along the segments of primary fracture can be seen in the right hand photograph.

Figure 11

Figure 11 shows three possible types of linkage of stepped segments propagating towards each other. In all cases the segments are combined in one fault by joining fractures within the linkage zone. $L_{j}$ and $h_{j}$ indicate correspondingly length and thickness of the joining factures. All of these fractures comprise block structures where behavior during displacement of the fault is consistent with the frictionless concept. The existence of joining fractures in the general fault facilitates accommodation of large displacements and decreases the fault resistance to shear. This contrasts with the traditional point of view according to which jogs and other forms of discontinuity represent high resistance barriers impeding static and dynamic fault propagation and motion.

\subsubsection{Jump-like fault propagation}

Advanced triggering of new fractures allows understanding the formation sequence of general faults with very complicated structure. Figure 12 presents seven stages of development of the fault, the photograph of which is shown in Figure 2b. A reduced copy of this photograph is located in the top right corner in Figure 12. The fault propagates upwards from the bottom and involves a number of primary fractures with significantly developed overlap zones. Contours of this fault are shown in the picture by dotted lines with bold arrows representing primary fractures, open arrows indicating the direction of shear and shaded areas representing joining fractures with a corresponding block structure. The orientation of rotating blocks of the fault structure relative to the fault axis is approximately the same in the diagram and in the photograph. Asterisks indicate centres of initiation of advanced triggered fractures.

Figure 12 
At stage-I a dynamically propagating primary fracture triggers an advanced fracture, the further development of which is shown at stage-II. This new fracture (as well as all further triggered fractures) propagates bilaterally towards the current fracture and in the opposite direction. This fracture in turn triggers the next advanced fracture shown at stage-III. At this stage the length of overlapping zone between the two bottom fractures has reached the critical value and the first joining fracture is created. The process of creating the joining fracture involves dynamic shear accompanied by jump-like displacement within this zone and stress relaxation in the surrounding area. Further fault development occurs through repetition of similar stages. Both processes governing the general fault development - advanced triggering and the formation of joining fractures have a jump-like character. Hence, jump-like propagation for general faults and wavelike (fan-shaped wave) propagation for primary fractures are two different natural forms of shear fracture development.

\subsubsection{Two-dimensional model}

Figure 13a illustrates the development of a general fault, initiated from a hypocentre shown by the asterisk. Due to stress transfer a set of new ruptures can be triggered in the vicinity of the first one. After linkage of these ruptures in one fault, the influence of the combined fault on the surrounding rock mass increases, which can trigger new ruptures (segments) at greater distance and so on. It should be noted that the triggered segments develop on the same principle of advanced triggering creating a self-similar structural hierarchy (see Figure 13b). This mechanism is therefore consistent with the fractal structure observed in natural faults at all scales [1]. Figure 13 shows symmetric location of segments in the general fault, although in reality this picture may be very chaotic. However, the main concept of its formation stays the same: the larger the fault grows, the greater is the chance to trigger new faults at greater distance; also the greater the distance the larger is the new activated segment. So, dimensions of segments increase with fault development from hypocentre to periphery. Although chaotic in detail the fault structure in general should be similar to that presented in Figure 13. When such complex fault reaches an open surface (axes $\mathrm{x}-\mathrm{x}$ or $\mathrm{y}-\mathrm{y}$ in Figure 13) its cross-section can be seen as an echelon of identical segments as shown in Figures 2b and 2c. 
Figure 13

It should be emphasized again that areas of linkage between segments where joining shear fractures are formed facilitate fault displacement and can significantly reduce the fault strength due to activation of the frictionless mechanism in these fractures. The larger is the proportion of linkage areas in the total fault plane the greater will be the influence of the frictionless mechanism on the fault resistance. Low strength of some existing faults [69-71] can be explained by this mechanism. Pictures in Figure 13 show that in some zones of the fault three or even four segments can intersect creating very complicated junctions. It should be noted also that the schema in Figure 13 illustrates the direct sequence of the general fault propagation, which is characterized by an increase in the segment size from the hypocentre to periphery. However, it is clear (and field observations verify this, [1] that the maximum fault displacement will be accumulated in the central part of the fault. This means that with further fault propagation additional fracture processes will be activated leading to significant and increasing damage of the central part of the fault.

\subsection{Speed trebling mechanism}

The average rupture speeds for most shallow crustal earthquakes range from 0.75 to $0.95 c_{R}$ where $c_{R}$ is the average Rayleigh wave speed in the surrounding crustal rock mass. However, considerable evidence of intersonic rupture speeds have been reported [18-21]. It is important to emphasize that earthquake ruptures represent general faults in our classification. Rock damage associated with general faults compared with primary fractures is significantly greater due to existence of linkage zones between segments. In this regard it appears paradoxical that intersonic speed is attainable for earthquake ruptures and has never been reported for primary fractures in rocks. This paradox can be explained if we analyze the mechanism of advanced triggering in more detail. The mechanism leads to a propagation speed for general faults that is three times that in primary fractures. Figure 14 illustrates this. 
Figure 14

The figure shows four stages of propagation of two different faults, which propagate from left to right (the horizontal axis representing distance). The first fault shown by dotted arrows develops as a primary fracture. Solid arrows represent the general fault propagating in accordance with the advanced triggering mechanism, with centres of triggered segments shown by asterisks. It is assumed that the speed of propagation of primary fractures in the general (complex) fault and in the first (simple, continuous) fault is the same. The total growth for the two modes of fault propagation, over the four stages considered, is indicated at the bottom of the figure, showing that the growth provided by the new mechanism is three times that for the conventional mode $\left(\Delta L_{\text {complex }}=3 \Delta L_{\text {simple }}\right)$. In this example, the distance $q$ between the fault edge and each new nucleation centre in the next segment was kept the same. It should be noted that the efficiency of the trebling mechanism does not depend on the value of $q$. However, we can expect that with the fault growth the distance $q$ should increase due to increasing influence of the growing fault on the stress regime in the surrounding rock mass.

Before making a final conclusion about the general fault speed, it is important to mention the following result of observations. It was found by Wyss and Brune [63] that the 1964 Alaska earthquake, propagated from east to west at a speed near the shear velocity, and consisted of a sequence of recognizable sub-events. The observed feature confirms that the nature of general fault propagation involves advanced triggering and the intersonic speed achievement is most likely a result of the trebling effect. Hence, to reach a speed of $5 \mathrm{~km} / \mathrm{s}$ the speed of primary fractures should be about $1.7 \mathrm{~km} / \mathrm{s}$. The result obtained looks realistic and explains the paradoxical combination of intersonic speed and severe damage of the rock mass within the fault zone.

Unlike the proposed intersonic mechanism where primary fractures involved in a general fault propagate subsonically, the existing theories [11-17,72] consider the attainability of intersonic speed for primary fractures. Despite the absolutely different physics involved in the proposed and existing intersonic mechanisms it is possible to find some similarities between them, for instance, the existence of the mother-daughter principle. The Burridge-Andrew mechanism proposes that a mother crack after 
propagating at the Rayleigh wave speed for a short time period nucleates an intersonic daughter crack. It happens when a peak of shear stress ahead of the mother crack tip reaches the cohesive material strength.

In the proposed mechanism a mother rupture propagates in the highly stressed material by inducing an-echelon of closely spaced neighboring cracks (mode-I cracks) in the rupture tip. Due to the stress transfer caused by the growing mother rupture a daughter rupture can be initiated at some distance ahead in a region that were themselves on the verge of shear. The daughter rupture propagates on the same manner and at the same speed as the mother rupture. The distance between the mother rupture tip and the daughter rupture hypocenter is determined by the mother rupture length, stress field and heterogeneity of the material strength.

\section{Conclusions}

This paper shows that hard rocks at high confining pressure acquire specific properties which distinguish them markedly from common rock behaviour - they become extremely brittle and lose shear resistance within a certain range of the shear rupture displacement. These hard rock features are caused by the intrinsic nature of the fault structure which is an echelon of blocks operating as hinges, essentially eliminating friction at high confining pressure. The frictionless concept allows the process of shear fracture development to be viewed from a new point of view.

A simple but well-founded classification of shear fractures is used in the paper, namely: i) primary fractures - continuous thin ruptures with uniform structure and ii) general faults - complex discontinuous systems. It is shown that despite the similarity in their structures, each of which is represented by an echelon of rotating blocks, the development of these two forms of fractures is drastically different.

The general faults propagate in a jump-like manner forming a cascade of segments (or primary fractures) due to an advanced triggering mechanism. The advanced triggering mechanism triples the propagation speed of the general fault compared with the speed of primary fractures involved in the fault. The propagation of primary ruptures is facilitated by another mechanism, which is a fan-shaped self-equilibrated mechanism created on the basis of an echelon of rotating blocks representing the intrinsic nature of 
the shear crack structure. These two mechanisms in combination can provide intersonic propagation of general faults.

The new approach allows looking at the nature of formation, interaction and linkage of segments from a novel unconventional point of view. In particular, according to the new interpretation, zones representing linkage between segments do not present obstacles for the fault propagation as is generally considered today. On the contrary, special structures formed in these zones facilitate the accommodation of large displacement of the general fault with minimum consumption of energy.

\section{Acknowledgements}

This work was supported during a number of years by the Australian Special Research Centre for Offshore Foundation Systems (COFS). This support is gratefully acknowledged. The author expresses his sincere gratitude to the founding Director of COFS, Professor Mark Randolph, for critical reviews of this paper and for helpful discussion during its preparation.

\section{References}

[1] Scholz CH. The mechanics of earthquakes and faulting. Cambridge: Cambridge University Press,2002.

[2] Ortlepp WD. Rock fracture and rockbursts. Johannesburg: The South African Institute of mining and metallurgy, 1997.

[3] Nur A. Nonuniform friction as a basis for earthquake mechanics. Pageoph 1978;116:964-989.

[4] Tse S, Rice J. Crustal earthquake instability in relation to the depth variation of frictional slip properties. J Geophys Res 1986;91:9452-9472.

[5] Freund LB. Dynamic fracture mechanics. Cambridge: Cambridge University Press, 1990.

[6] Broberg KB. Cracks and Fracture. San Diego: Academic Press, 1999.

[7] Washabaugh PD, Knauss WG. A reconciliation of dynamic crack velocity and Rayleigh wave speed in isotropic brittle solids. Int J Fract 1994;65:97-114.

[8] Ravi-Chandar K, Knauss WG. An experimental investigation into dynamic fracture: I. Crack initiation and arrest. Int J Fract 1984;25:247-262. 
[9] Johnson E. Process region changes for rapidly propagating cracks. Int J Fract 1992;55:47-63.

[10] Gao H. Surface roughening and branching instabilities in dynamic fracture. J Mech Phys Solids 1993;41;N3:457-486.

[11] Andrews D. Rupture velocity of plane strain shear cracks. J Geophys Res 1976;81:5679-5687.

[12] Freund LB. The mechanics of dynamic shear crack propagation. J Geophys Res 1979;84:2199-2209.

[13] Broberg KB. The near-tip field at high crack velocities. Int J Fract 1989;39:1-13.

[14] Gao H, Huang Y, Abraham FF. Continuum and atomistic studies of intersonic crack propagation. J Mech Phys Solids 2001;49:2113-2132.

[15] Samudrala O, Huang Y, Rosakis AJ. Subsonic and intersonic mode II crack propagation with a rate-dependent cohesive zone. J Mech Phys Solids 2002;50:12311268.

[16] Rosakis AJ, Samudrala O, Coker D. Cracks faster than the shear wave speed. Science 1999;284:1337-1340.

[17] Rosakis AJ. Intersonic shear cracks and fault ruptures. Advances in Physics 2002;51:No. 4:1189-1257.

[18] Archuleta RJ. Analysis of near source static and dynamic measurements from the 1979 Imperial Valley earthquake. Bull Seismol Soc Am 1982;72:1927-1956.

[19] Olsen KB, Madariaga R, Archuleta RJ. Three-dimensional dynamic simulation of the 1992 Landers eqrthquake. Science 1997;278:834-838.

[20] Ellswarth WL, Celebi M. Near-field displacement time histories of the M 7.4 Kocaeli (Izimit), Turkey, earthquake of August 17, 1999. Eos Trans AGU, 80(46), Fall Meet Supp. 1999;F648.

[21] Hernandez B, Cotton F, Campillo M. Contribution of radar interferometry to a two-step inversion of the kinematic process of the 1992 Landers earthquake. J Geophys Res 1999;104:13083-13099.

[22] Tarasov BG, Randolph MF. Frictionless shear at great depth and other paradoxes of hard rocks. Int J Rock Mech Min Sci 2007 (accepted for publication). 
[23] Brace W F, Bombolakis E G. A note on brittle crack growth in compression. J. Geophys Res 1963;68:3709-3713.

[24] Stavrogin AN. Study of ultimate strength and strain of rocks. Physics of Earth, AN SSSR 1969;12:54-69.

[25] Peng S, Johnson AM. Crack growth and faulting in cylindrical specimens of Chemsfold granite. Int J Rock Mech Min Sci Geomech Abstr 1972;9:37-86.

[26] Horii H, Nemat-Nasser S. Compression-induced micro-crack growth in brittle solids: Axial splitting and shear failure. J Geophys Res 1985;90:3105-3125.

[27] Ashby MF, Hallam SD. The failure of brittle solids containing small cracks under compressive stress states. Acta Metall 1986;34:497-510.

[28] Stavrogin AN, Tarasov BG. Experimental Physics and Rock Mechanics. India: Balkema, 2001.

[29] Moore DE, Summers R, Byerlee JD. Faults, fractures and other deformation features produced during loading of granite in triaxial equipment, U.S. Geol. Surv. Open File Pep 1990;290-349.

[30] Lockner DA, Byerlee JD, Kuksenko V, Ponomarev A, Sidorin A. Quasi-static fault growth and shear fracture energy in granite. Nature 1991;350:39-42.

[31] Reches Z, Lockner DA. Nucleation and growth of faults in brittle rocks. J Geophys Res 1994;99;B9:18.159-18.173.

[32] Lawn BR, Wilshaw TR. Fracture of Brittle Solids New York: Cambridge University Press, 1975.

[33] Pollard DD, Segall P. Theoretical displacements and stresses near fractures in rock with applications to faults, joints, veins, dikes, and solution surfaces. In: Fracture Mechanics of Rock, BK Atkinson, ed. San Diego, Calif: Academic, 1987, pp 277349.

[34] Ashby MF, Sammis CG. The damage mechanics of brittle solids in compression. Pure Appl Geophys, 1990;133: 489-521.

[35] King GCP, Sammis CG. The mechanisms of finite brittle strain. Pageoph 1992;138:611-639.

[36] Mandel G. Faulting in brittle rocks. Springer-Verlag Berlin Heidelberg, 2000. 
[37] Segall P, Pollard DD. The mechanics of discontinuous faults, J Geophys Res 1980;85:4337-4250..

[38] Petit J P, Barquins M. Can natural faults propagate under mode II conditions? Tectonics 1988;7:1243-1256.

[39] Moore $\mathrm{DE}$, Lockner $\mathrm{AD}$. The role of micro-cracking in shear fracture propagation in granite. J Struct Geol 1995;17:95-114.

[40] Vermilye JM, Scholz CH. Fault propagation and segmentation: insight from the microstructural examination of a small fault. J Struct Geol 1999;21:1623-1636.

[41] Sibson RH. Stopping of earthquake ruptures at dilatational jogs. Nature 1985;316: 248-251.

[42] Harris RA, Day SM. Dynamics of fault interaction: parallel strike-slip faults. J Geophys Res 1993;98: 4461-4472.

[43] Winkler S, Curran DR, Shockey DA. Crack propagation at supersonic velocities. Int J Fract 1970;6: 151-158.

[44] Ida Y. Stress concentration and unsteady propagation of longitudinal shear cracks. J Geophys Res 1982;77: 3796-385.

[45] Das S. Application of dynamic shear crack models to the study of the earthquake faulting process. Int J Fract 1985;27:263-276.

[46] Domowska R, Rice JR. Continuum theories in solid earth physics. Amsterdam: Elsevier, 1986, pp1881-1902.

[47] Rice JR. New perspectives on crack and fault dynamics in Mechanics for a New Millennium. In: The $20^{\text {th }}$ International Congress of Theoretical and Applied Mechanics, H Aref, JW Phillips, ed. Dordrecht: Kluwer, 2001, pp 1-23.

[48] Weertman J. Unstable slippage across a fault that separates elastic media of different elastic constants. J Geophys Res 1980;85:1455.

[49] Heaton TH. Evidence for and implications of self-healing pulses of slip in earthquake rupture. Physics of the Earth and Planetary Interiors, 1990;64:1-20.

[50] Ben-Zion Y, Andrews, D.J. Properties and implications of dynamic rupture along a material interface. Bull Seismol Soc Am 1998;88:1085-1094.

[51] Kanamori H, Brodsky EE. The physics of earthquakes. Physics Today 2001;54:34-40. 
[52] Clayton L. Tectonic depressions along the Hase fault, a transcurrent fault in north Canterbury, New Zealand, N Z J Geol Geophys 1966;9: 94-104.

[53] Sharp RV, Clark MM. Geologic evidence of previous faulting near the 1968 rupture on the Coyote Creed fault. U S Geol Surv Proof Pap 1972;787:131-140.

[54] Segall P, Pollard DD. Nucleation and growth of strike-slip faults in granite. J Geophys Res 1983;88:555-568.

[55] Granier T. Origin, damping and pattern of development of faults in granite. Tectonics 1985;4:721-737.

[56] Poliakov ANB, Domowska R, Rice JR. Dynamic shear rupture interactions with fault bends and off-axis secondary faulting. J Geophys Res 2002;107;B11, 2295, doi 10.1029/2001JB000572, ESE 6-1-6-18.

[57] Sibson RH. Rupture interaction with fault jogs. In: Earthquake source mechanisms, S Das, J Boatwright, CH Scholz, ed. Washington: Americal Geophysical Union, 1986.

[58] Burgmann R, Pollard DD, Martel SJ. Slip distributions on faults: effects of stress gradients, inelastic deformation, heterogeneous host-rock stiffness, and fault interaction. J Struct Geol 1994;16:1675-1690.

[59] Harris RA. Introduction to special section: Stress triggers, stress shadows, and implications for seismic hazard. J Geophys Res Solid Earth 1998;103:24347-24358.

[60] Stain RS. The role of stress transfer in earthquake occurrence. Nature 1999;402:605-609.

[61] King GCP, Cocco M. Fault interaction by elastic stress changes; new clues from earthquake sequences. Advances in Geophys 2000;44:1-38.

[62] Ziv A, Rubin AM. Static stress transfer and earthquake triggering: no lower threshold in sight. J Geophys Res 2000;105:13631-13642.

[63] Wyss M, Brune J. The Alaska earthquake of 28 March 1964: A complex multiple rupture. Bull Seismol Soc Am 1967;57:1017-1023.

[64] Andrews D. A stochastic fault model, static case. J Geophys Res 1980;85:38673887.

[65] Hanks T, McGuire R. The character of high-frequency strong ground motion. Bull Seismol Soc Am 1981;71:2071-2095. 
[66] Das S, Aki K. A numerical study of two-dimensional spontaneous rupture propagation. Geophys J Roy Astr Soc 1977;50:643-668.

[67] Aki K Characterization of barriers of an earthquake fault. J Geophys Res 1979;84:6140-6148.

[68] Day S. Three-dimensional simulation of spontaneous rupture: the effect on nonuniform prestress. Bull Seismol Soc Am 1982;72:1881-1902.

[69] Zobak MD. New evidence on the state of stress of the San Adreas fault system. Science 1987;238:1105-1111.

[70] Hickman SH. Stress in the lithosphere and the strength of active faults. Rev Geophys 1991;29:759-775.

[71] Sleep NH, Blanpied ML. Creep, compaction and the weak rheology of major faults. Nature 1992;359:687-692.

[72] Burridge R. Admissible speeds for plane-strain self-similar shear cracks with friction but lacking cohesion. Geophys J Roy Asgr Soc 1973;35:439-455.

\section{Figure legends}

Figure 1. The shear rupture model by Reches and Lockner [31]. a) The geometry of three mode-I cracks forming the process zone of shear rupture. b) Idealized shear rupture model comprising the process and core zones. (Figure 1 presents a combination of two figures from [31]).

Figure 2. a) Primary shear rupture and b, c) general faults initiated in quartzite at a 2000 m deep mine (from Ortlepp [2]).

Figure 3. Features of hard rock behaviour at high confining pressure exceeding some critical level $\sigma_{3}>\sigma_{3}{ }^{c r}$. For the tested dolerite specimens $\sigma_{3}{ }^{\mathrm{cr}} \approx 50 \mathrm{MPa}$

Figure 4. Idealized concept of the frictionless fault displacement in hard rocks at high confining pressure. a) Fragment of shear fracture at different stages of displacement; b) Interrelation between fault resistance $\mathrm{F}^{\prime}$, reactive normal force $\mathrm{N}^{\prime}$ and angle $\beta$; c) Normalized fault resistance $\mathrm{F}^{\prime} / \mathrm{N}^{\prime}$ versus angle $\beta$ at the fault displacement.

Figure 5. Idealized model of shear fracture propagation governed by the fan-shaped mechanism

Figure 6. Fan-shaped structure as a self-compensating mechanism 
Figure 7. Hackly surface of a shear plane representing footprints of rotating blocks (from Ortlepp [2]).

Figure 8. Model of two-dimensional shear fracture development.

Figure 9. Interaction between preceding and subsequent segments of the fault in accordance with a) common concepts and b) new approach.

Figure 10. Linkage of stepped segments propagating in opposite directions (photographs from Ortlepp [2])

Figure 11. Three possible types of the linkage of stepped segments propagating in opposite directions.

Figure 12. Cascade-like fault propagation due to advancing rupture triggering.

Figure 13. Model of the complex fault formation.

Figure 14. Illustration of the speed trebling mechanism. 
(a)

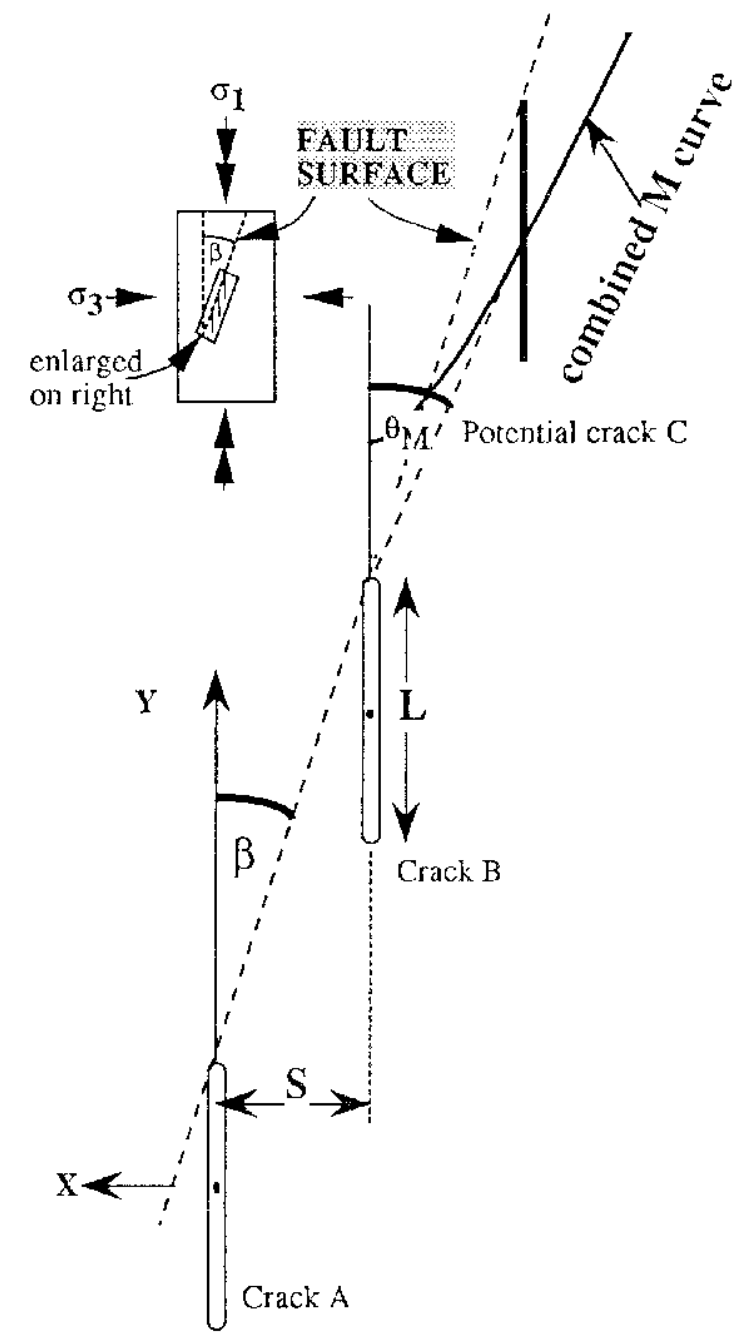

(b)

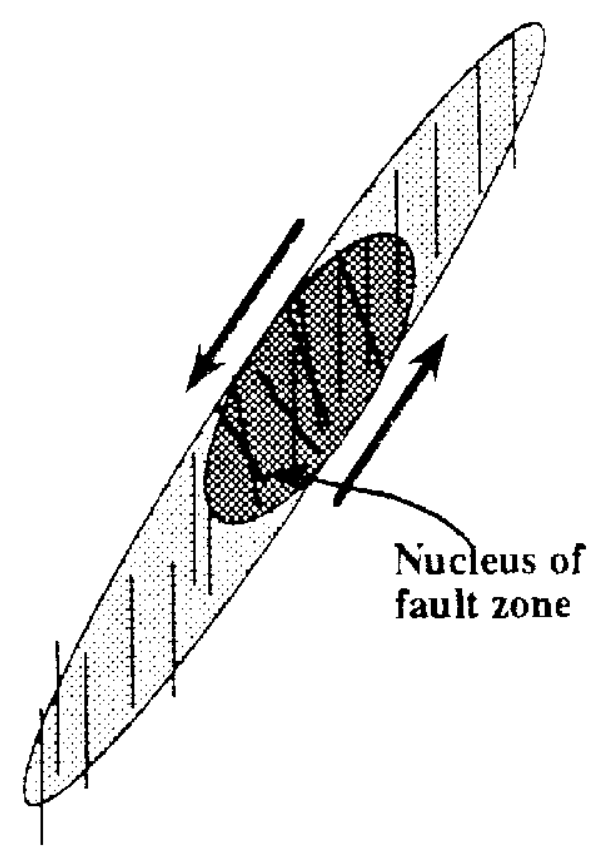

Figure 1. The shear rupture model by Reches and Lockner [31]. a) The geometry of three mode-I cracks forming the process zone of shear rupture; b) Idealized shear rupture model comprising the process and core zones.

(Figure 1 presents combination of two figures from [31]). 
a)
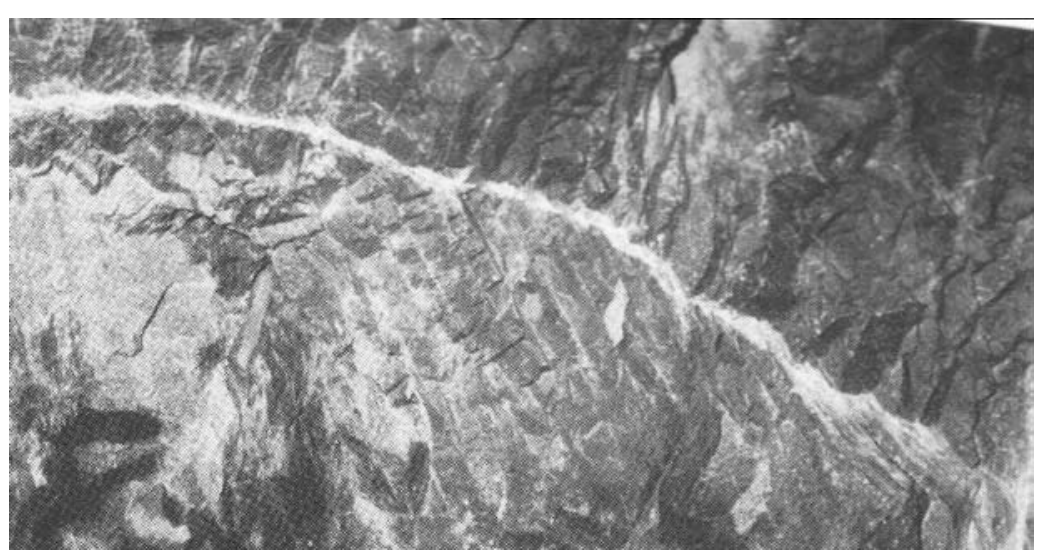

c)

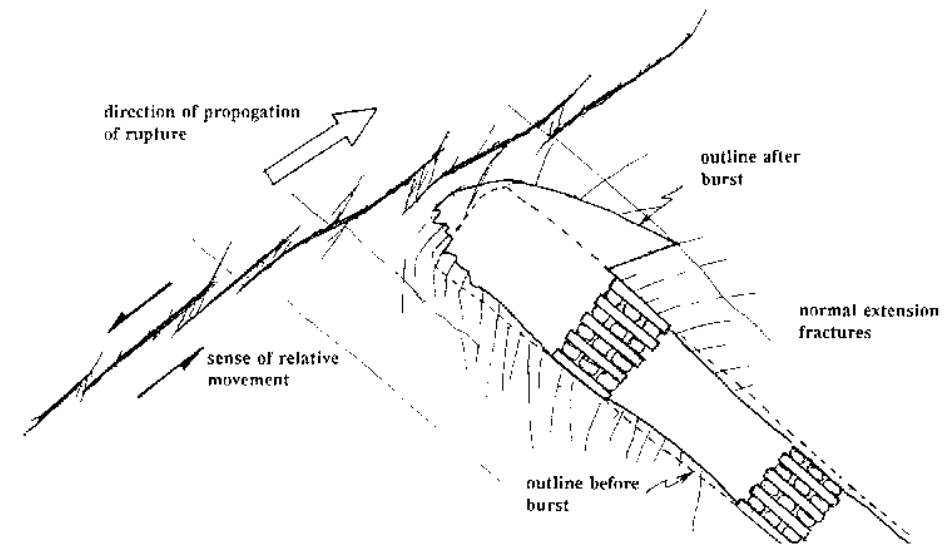

b)

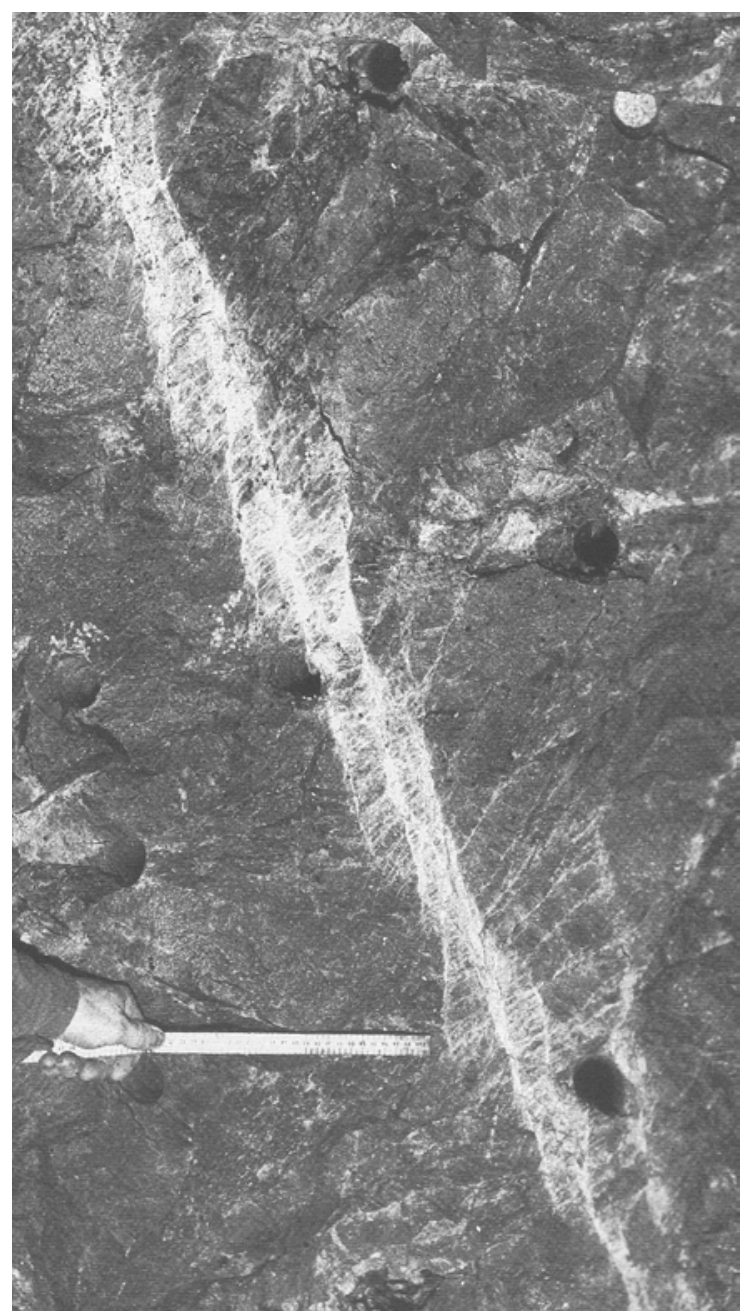

Figure 2. a) Primary shear rupture and b, c) general faults initiated in quartzite at a $2000 \mathrm{~m}$ deep mine (from Ortlepp [2]). 
$30 \mathrm{MPa}$

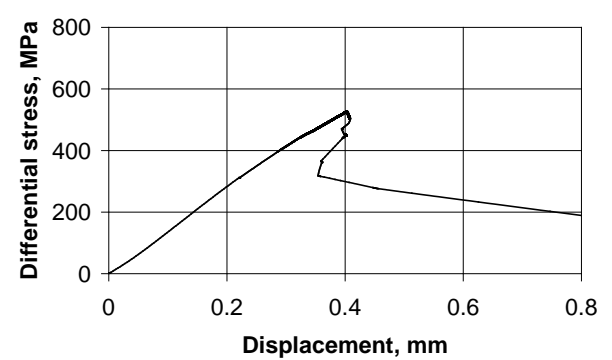

Displacement, $\mathrm{mm}$

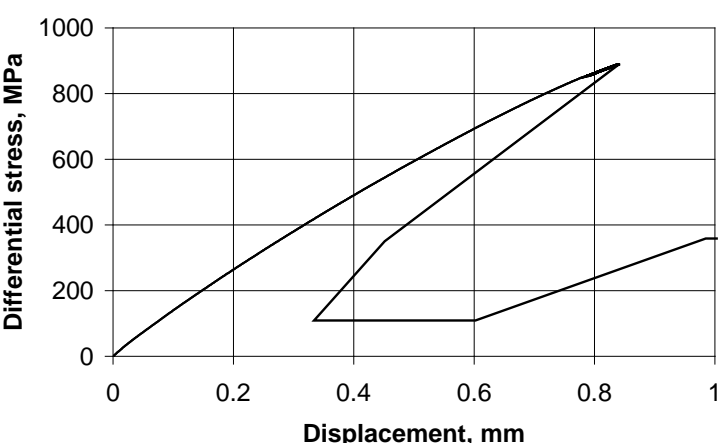

$100 \mathrm{MPa}$
$60 \mathrm{MPa}$

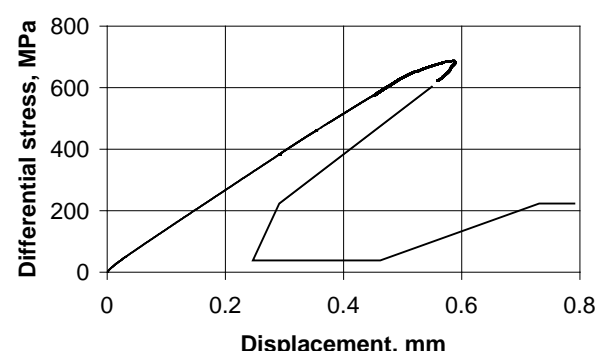

$75 \mathrm{MPa}$

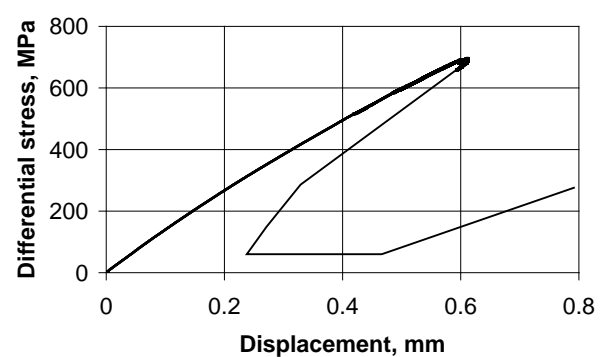

$150 \mathrm{MPa}$

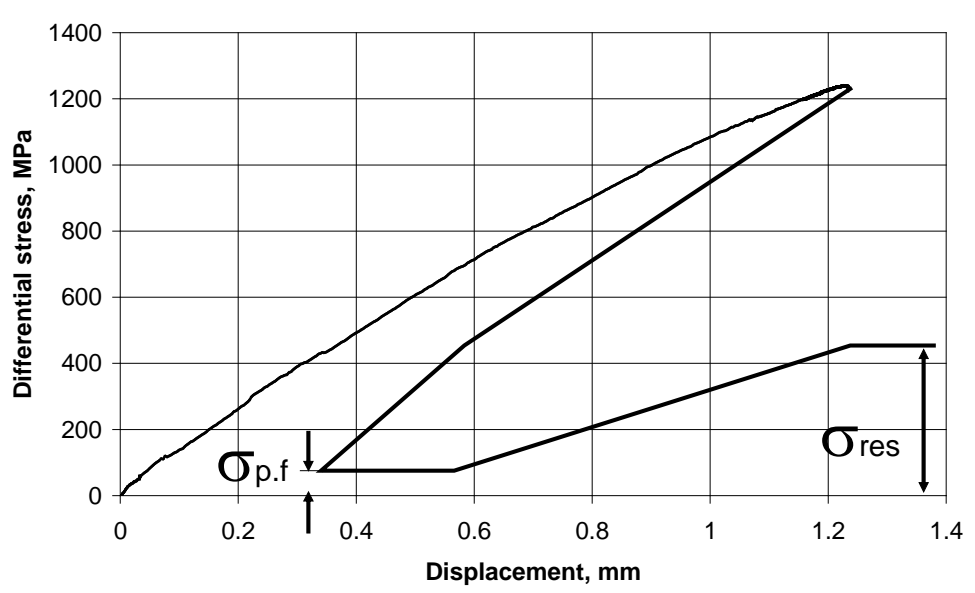

Figure 3 Features of hard rock behaviour at high confining pressure exceeding some critical level $\sigma_{3}>\sigma_{3}{ }^{\mathrm{cr}}$. For the tested dolerite specimens $\sigma_{3}{ }^{\mathrm{cr}} \approx 50 \mathrm{MPa}$ 
(i)

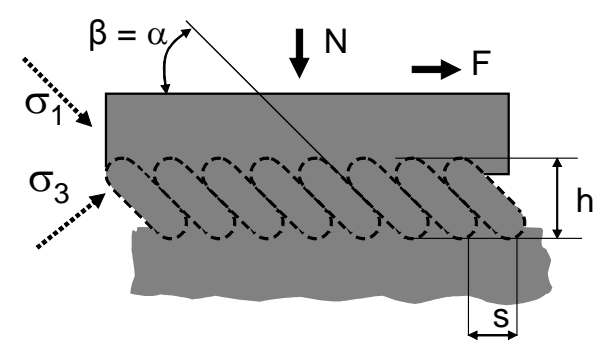

a)

(iii)

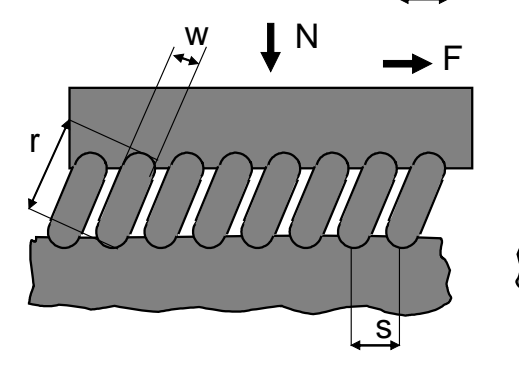

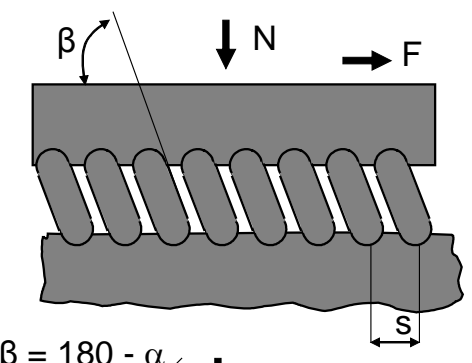

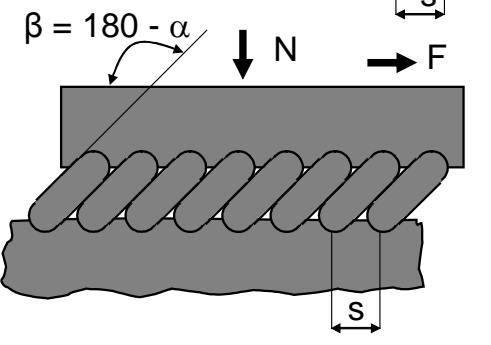

(ii)

b)

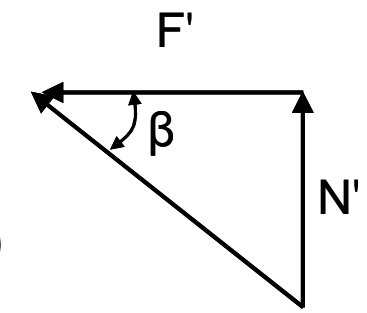

c)

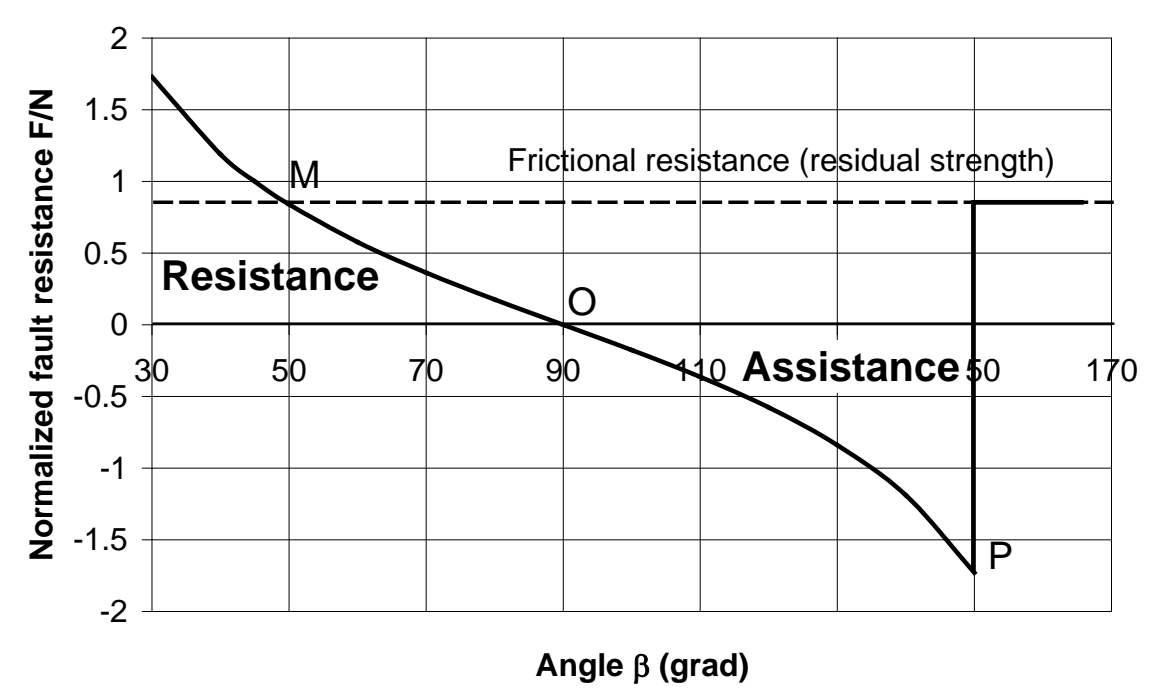

Figure 4. Idealized concept of the frictionless fault displacement in hard rocks at high confining pressure. a) Fragment of shear fracture at different stages of displacement; b) Interrelation between fault resistance F', reactive normal force N' and angle $\beta$; c) Normalized fault resistance F'/N'versus angle $\beta$ at the fault displacement. 
a) $\left.\downarrow \alpha \downarrow \downarrow \sigma_{1} \downarrow \downarrow \downarrow \downarrow \tau\right) \downarrow$

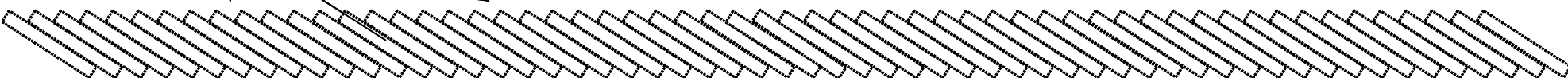

b)

$$
\sigma_{3}
$$

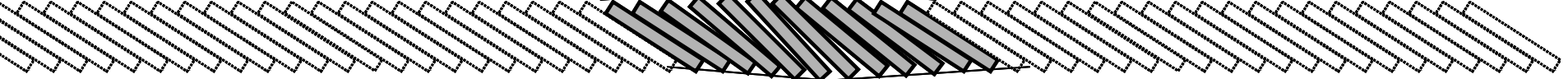

c)

d)

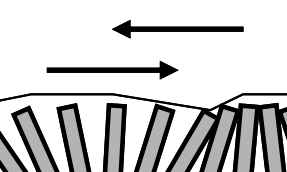

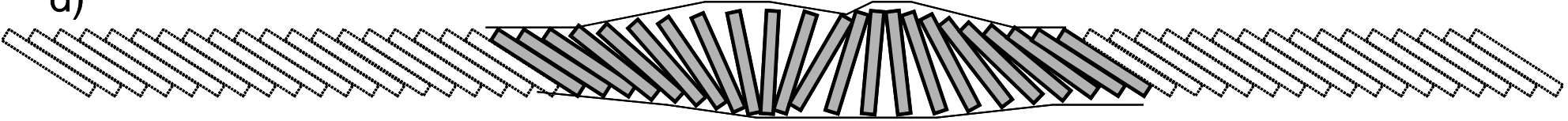

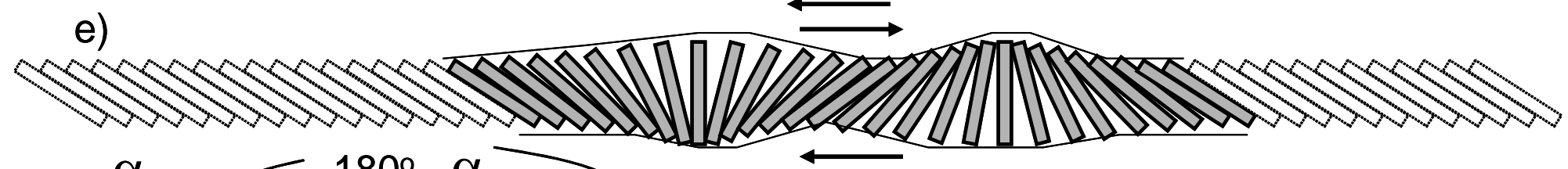

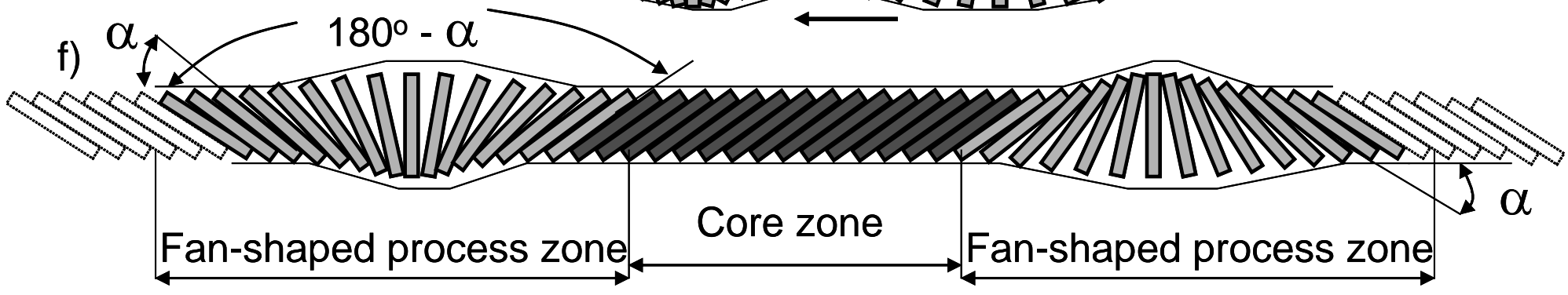

Figure 5. Idealized model of shear fracture propagation governed by the fan-shaped mechanism 
a)

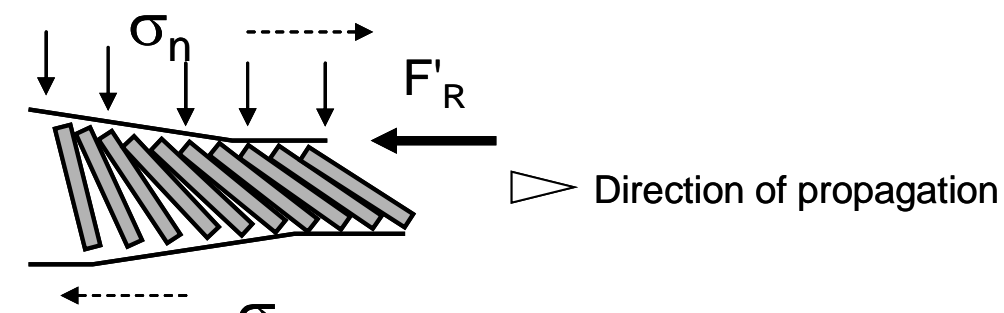

b)

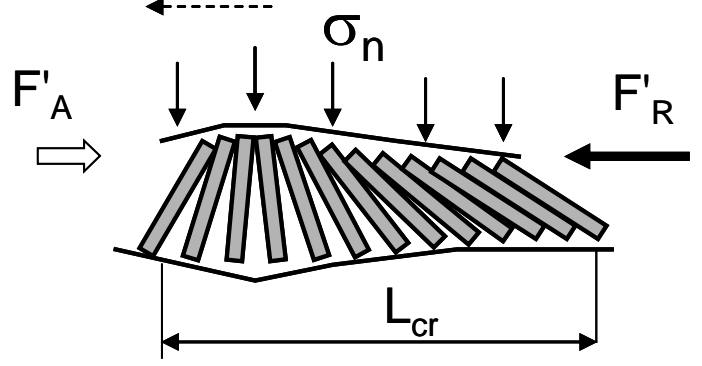

c)

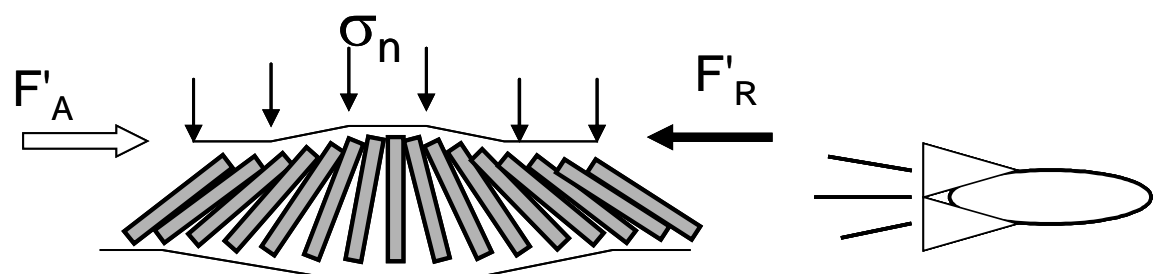

Compression zone

d)
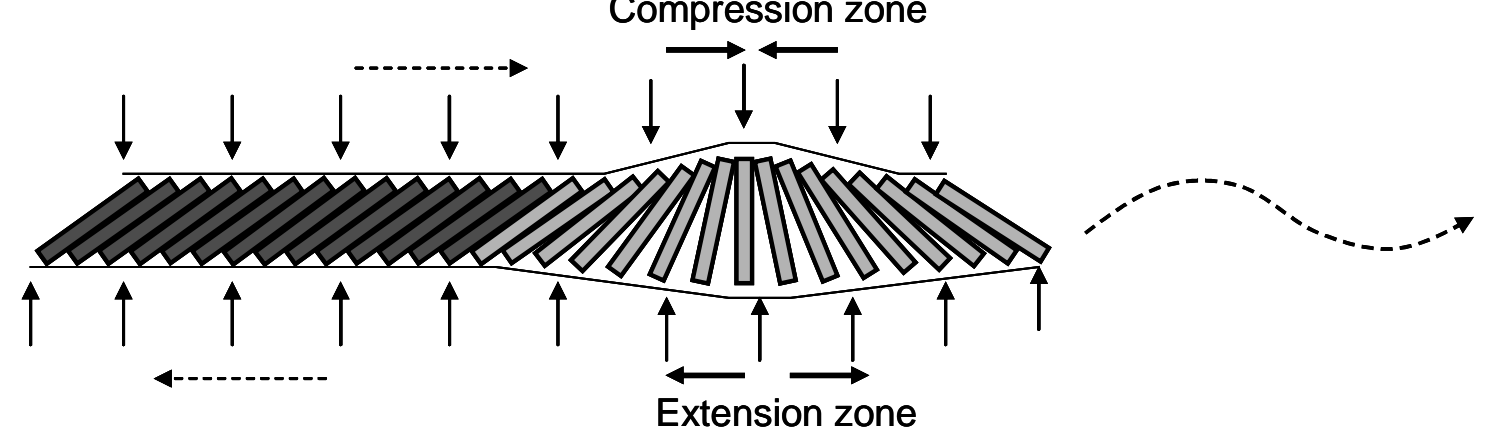

Figure 6. Fan-shaped structure as a self-compensating mechanism 


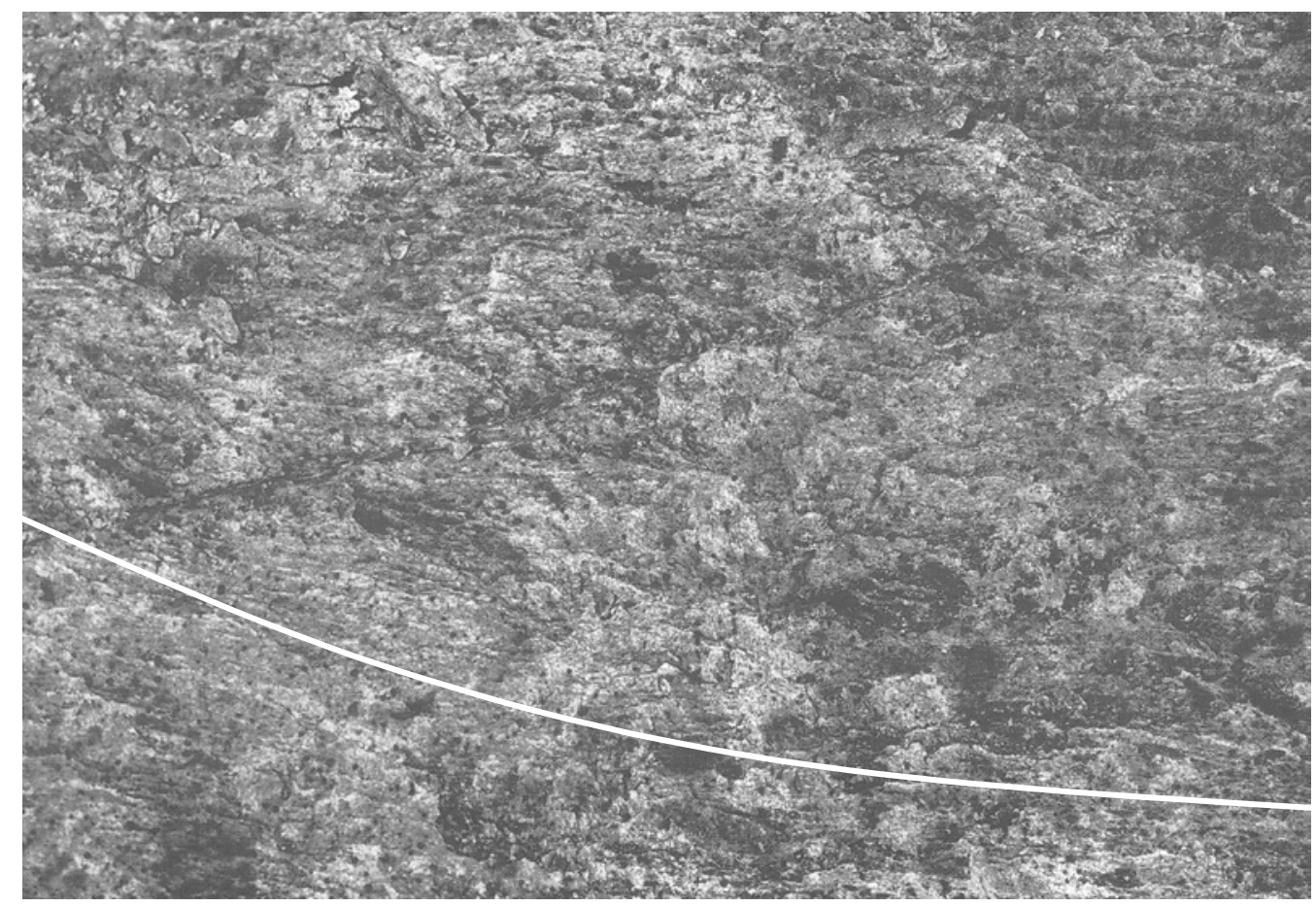

Figure 7. Hackly surface of a shear plane representing footprints of rotating blocks (from Ortlepp [2]). 


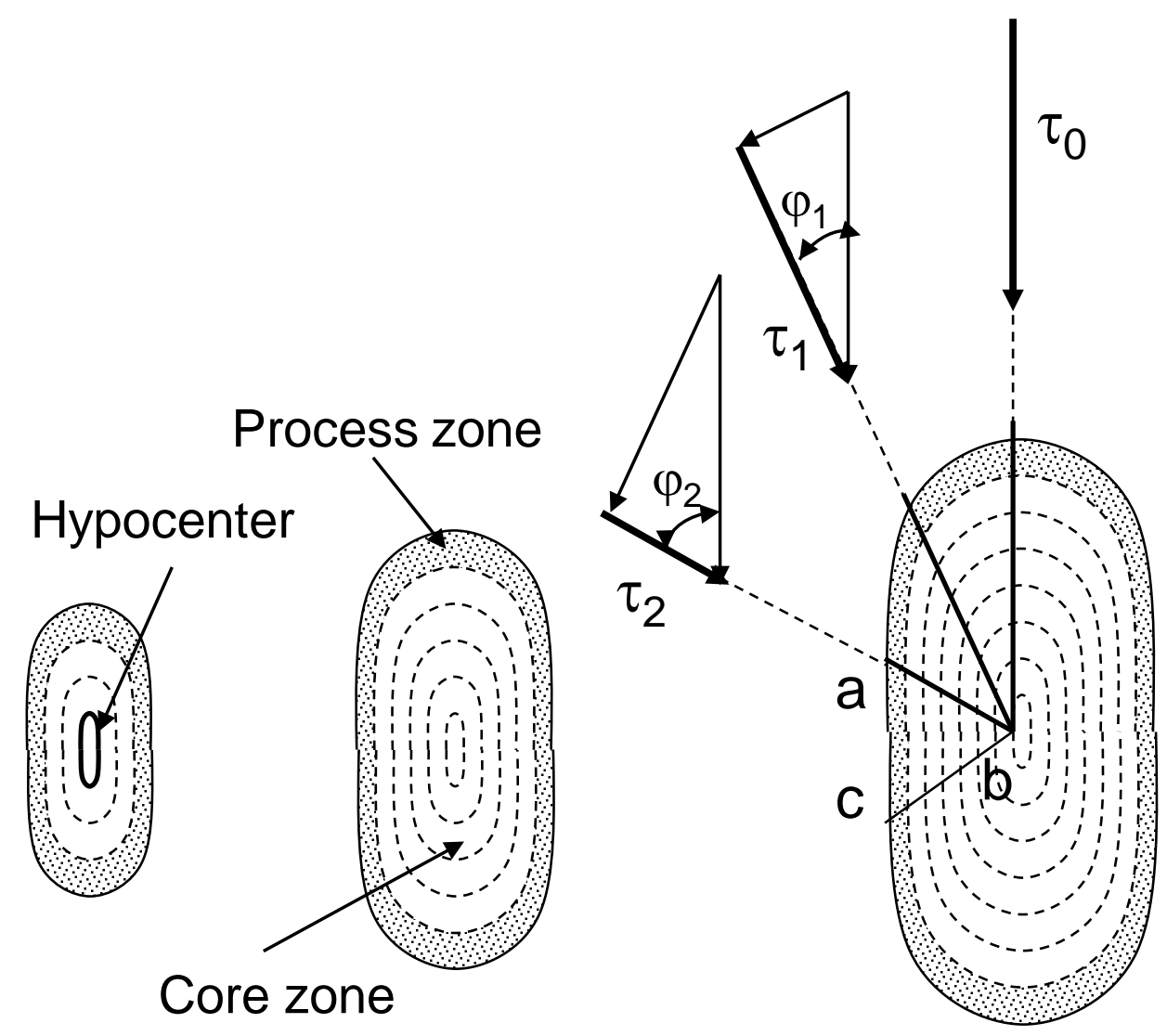

Figure 8. Model of two-dimensional shear fracture development. 


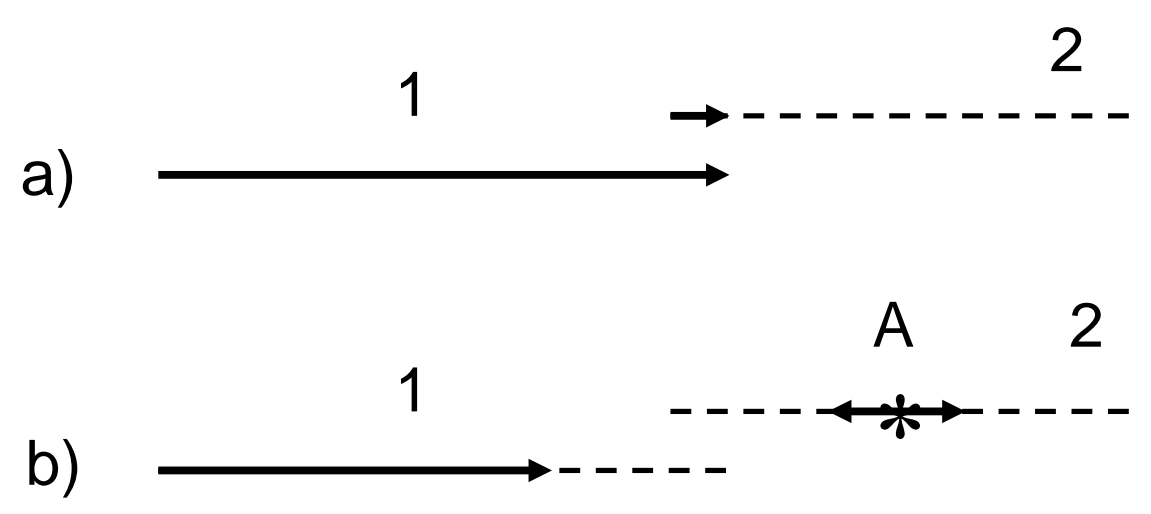

Figure 9. Interaction between preceding and subsequent segments of the fault in accordance with a) common concepts and b) new approach 


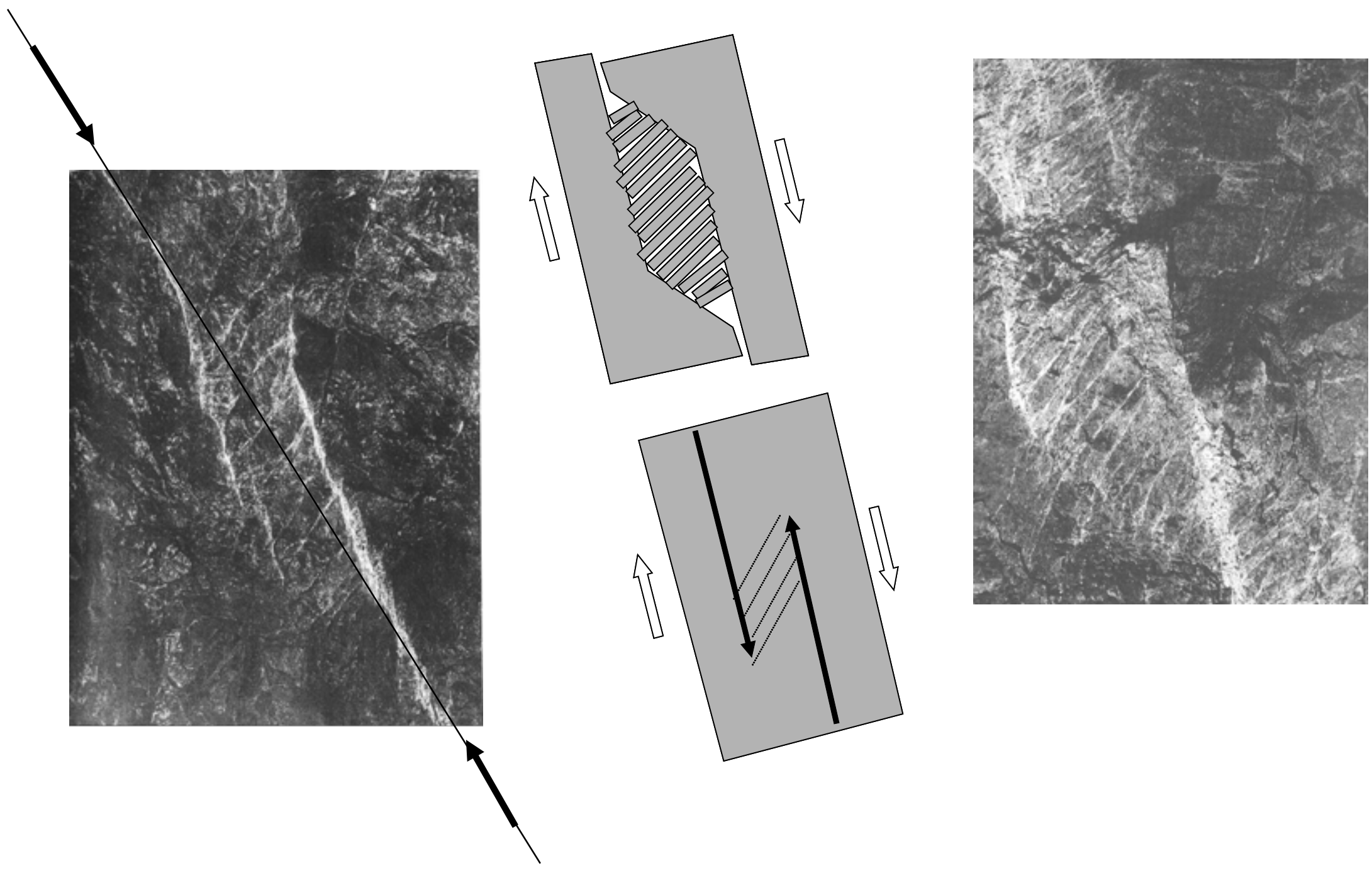

Figure 10. Linkage of stepped segments propagating in opposite directions (photographs from Ortlepp [2]. 


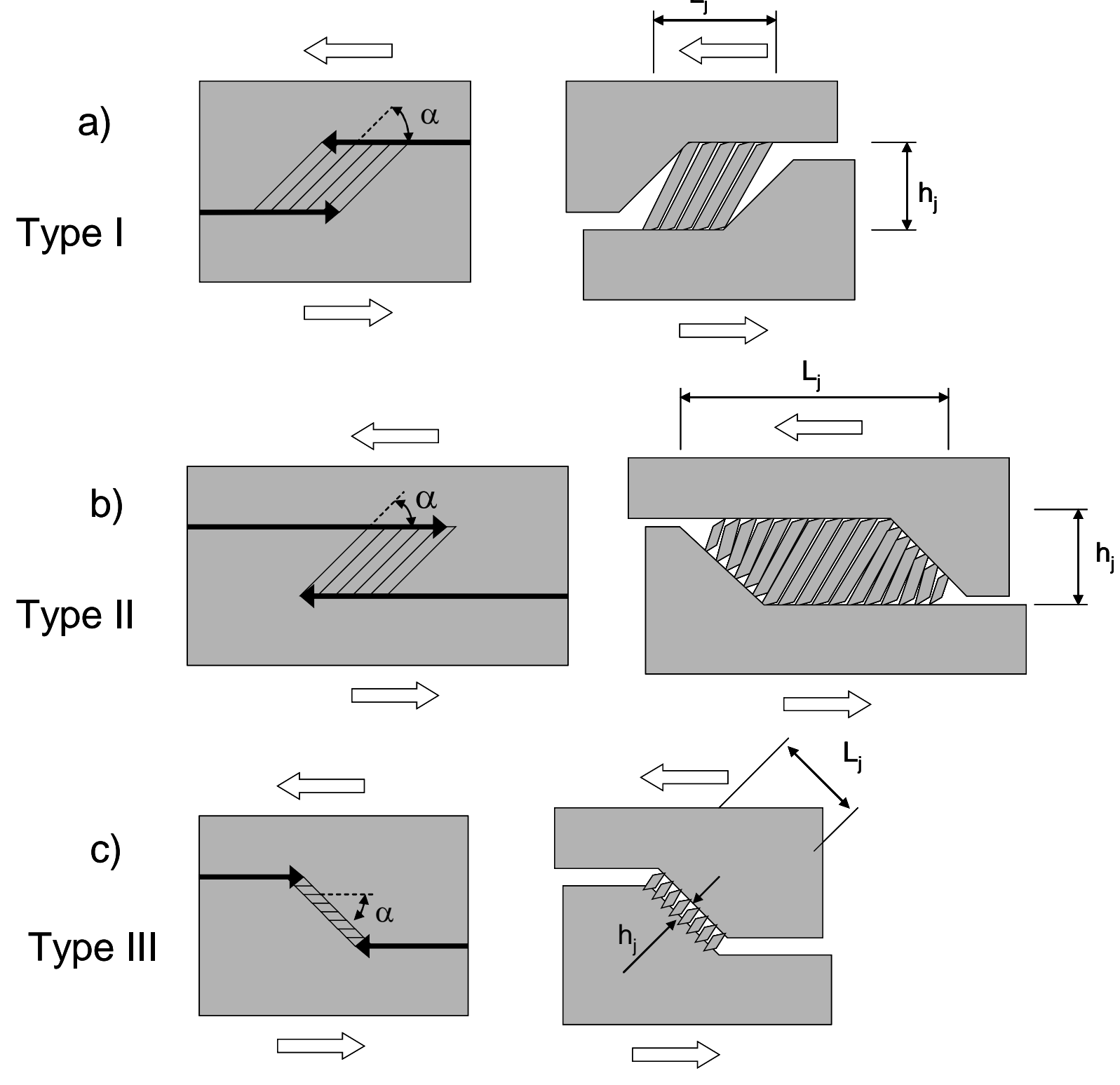

Figure 11. Three possible types of the linkage of stepped segments propagating in opposite directions. 


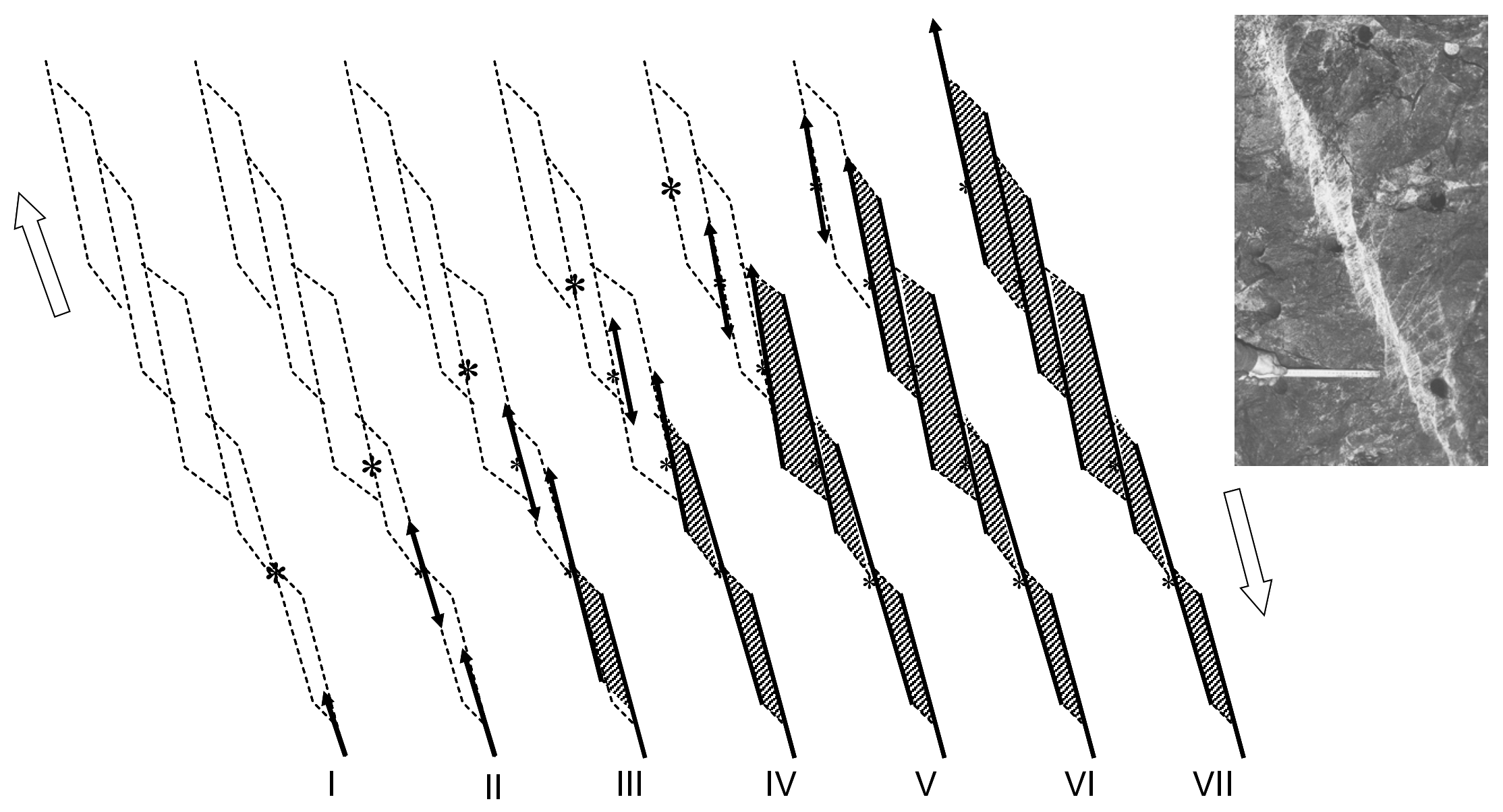

Figure 12. Cascade-like fault propagation due to advancing rupture triggering 


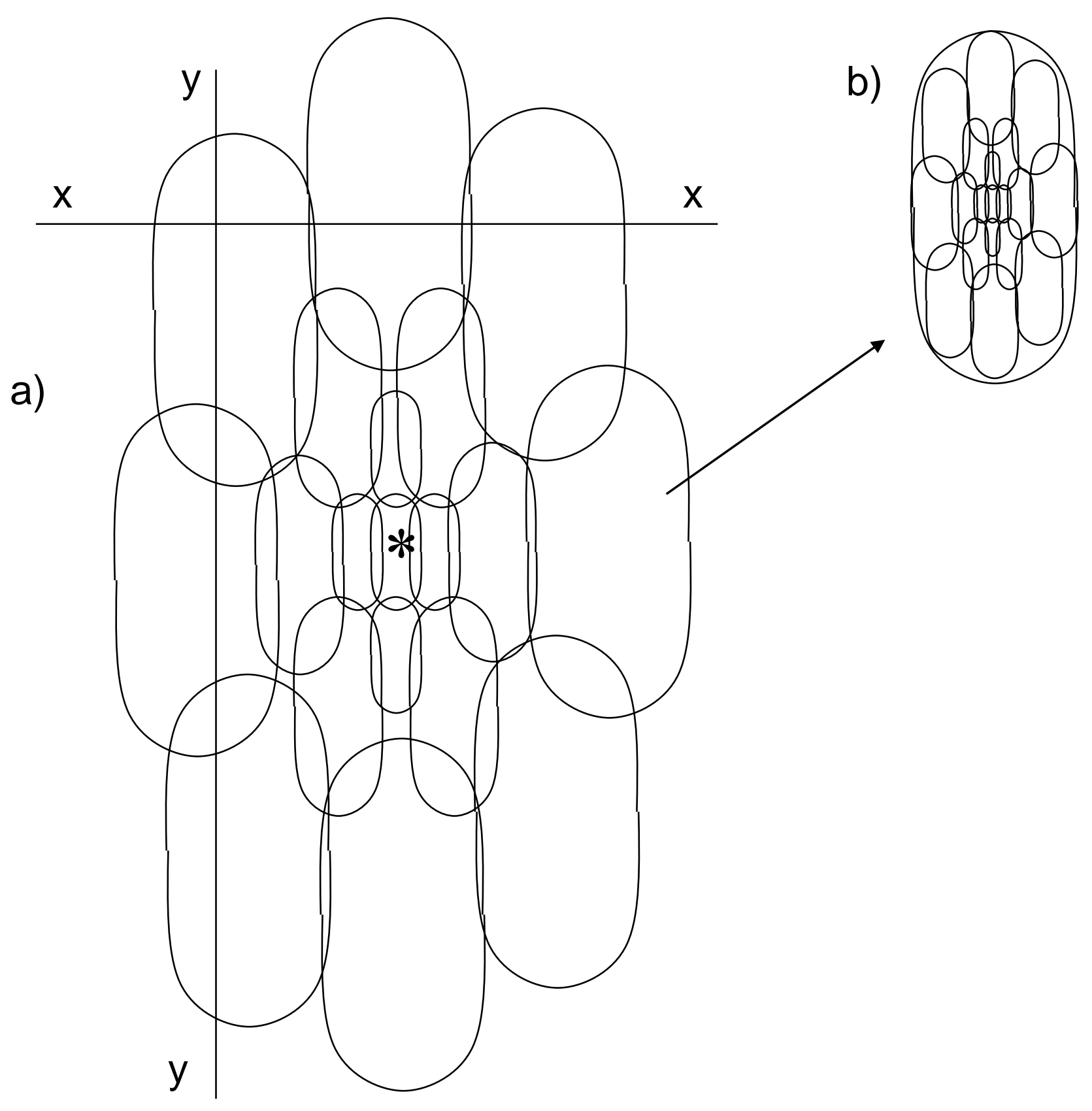

Figure 13. Model of the complex fault formation 


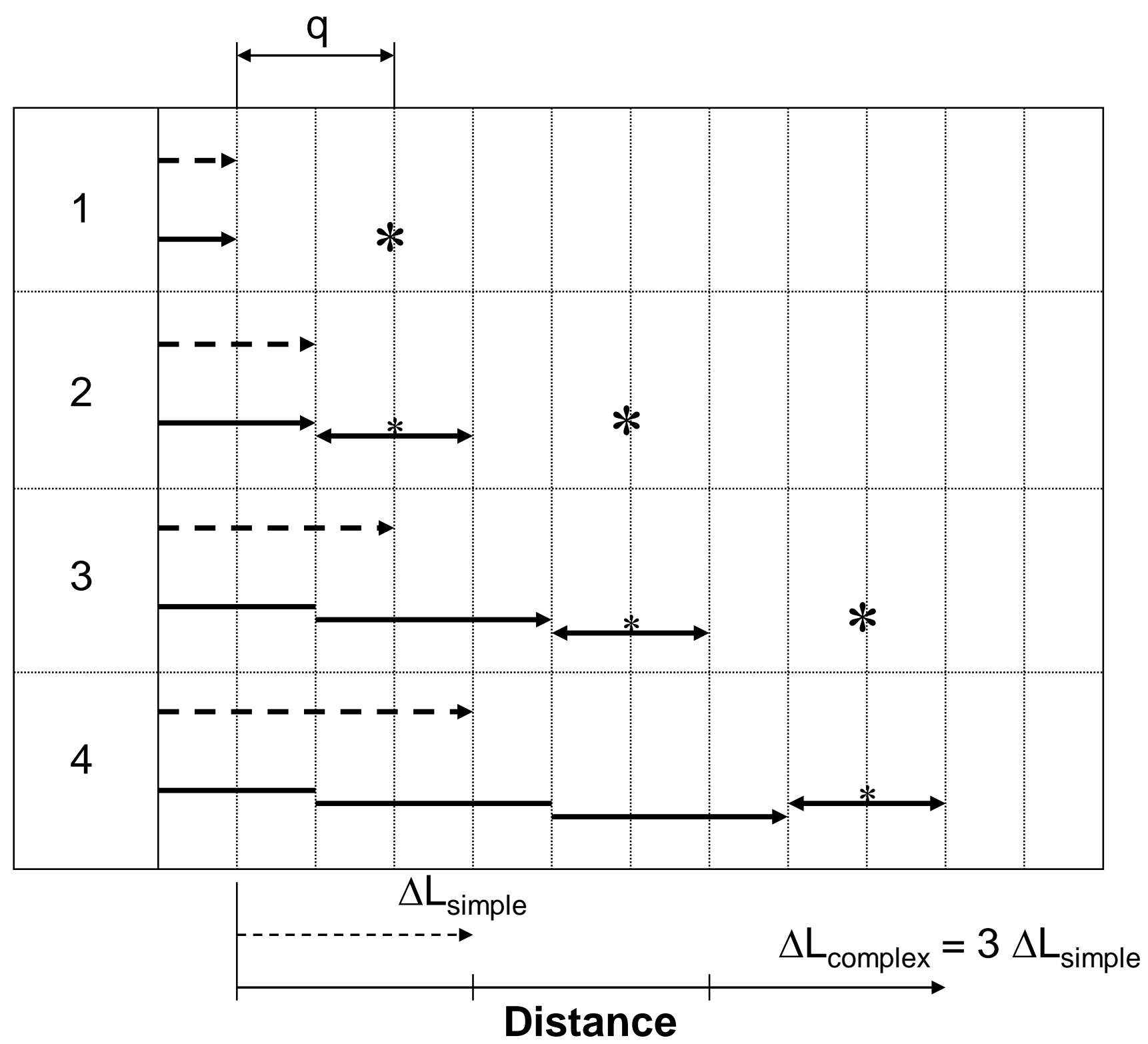

Figure 14. Illustration of the speed trebling mechanism 